\title{
Human TRIM5 $\alpha$ : Autophagy Connects Cell-Intrinsic HIV-1 Restriction and Innate Immune Sensor Functioning
}

\author{
Alexandra P. M. Cloherty ${ }^{+}\left(\mathbb{D}\right.$, Anusca G. Rader $^{+}(\mathbb{D}$, Brandon Compeer and Carla M. S. Ribeiro *(D) \\ Amsterdam UMC, University of Amsterdam, Department of Experimental Immunology, Amsterdam Institute for \\ Infection \& Immunity, Meibergdreef 9, 1105 AZ Amsterdam, The Netherlands; \\ a.p.cloherty@amsterdamumc.nl (A.P.M.C.); a.g.rader@amsterdamumc.nl (A.G.R.); \\ brandoncompeer@hotmail.com (B.C.) \\ * Correspondence: c.m.ribeiro@amsterdamumc.nl \\ † These authors contributed equally to this work.
}

Citation: Cloherty, A.P.M.; Rader, A.G.; Compeer, B.; Ribeiro, C.M.S. Human TRIM5 $\alpha$ : Autophagy Connects Cell-Intrinsic HIV-1 Restriction and Innate Immune Sensor Functioning. Viruses 2021, 13, 320. https://doi.org/10.3390/v13020320

Academic Editor: Sébastien Nisole

Received: 8 January 2021

Accepted: 13 February 2021

Published: 19 February 2021

Publisher's Note: MDPI stays neutral with regard to jurisdictional claims in published maps and institutional affiliations.

Copyright: (C) 2021 by the authors. Licensee MDPI, Basel, Switzerland. This article is an open access article distributed under the terms and conditions of the Creative Commons Attribution (CC BY) license (https:/ / creativecommons.org/licenses/by/ $4.0 /)$.

\begin{abstract}
Human immunodeficiency virus-1 (HIV-1) persists as a global health concern, with an incidence rate of approximately 2 million, and estimated global prevalence of over 35 million. Combination antiretroviral treatment is highly effective, but HIV-1 patients that have been treated still suffer from chronic inflammation and residual viral replication. It is therefore paramount to identify therapeutically efficacious strategies to eradicate viral reservoirs and ultimately develop a cure for HIV-1. It has been long accepted that the restriction factor tripartite motif protein 5 isoform alpha (TRIM5 $\alpha$ ) restricts HIV-1 infection in a species-specific manner, with rhesus macaque TRIM5 $\alpha$ strongly restricting HIV-1, and human TRIM5 $\alpha$ having a minimal restriction capacity. However, several recent studies underscore human TRIM $5 \alpha$ as a cell-dependent HIV-1 restriction factor. Here, we present an overview of the latest research on human TRIM $5 \alpha$ and propose a novel conceptualization of TRIM $5 \alpha$ as a restriction factor with a varied portfolio of antiviral functions, including mediating HIV-1 degradation through autophagy- and proteasome-mediated mechanisms, and acting as a viral sensor and effector of antiviral signaling. We have also expanded on the protective antiviral roles of autophagy and outline the therapeutic potential of autophagy modulation to intervene in chronic HIV-1 infection.
\end{abstract}

Keywords: TRIM5 $\alpha$; autophagy; HIV-1 restriction; viral evasion; antiviral immunity; Langerhans cells; Langerin; dendritic cells; macrophages; $\mathrm{CD}^{+} \mathrm{T}$ cells

\section{HIV-1 Infection: Decades after Implementation of Antiretroviral Therapy}

Human immunodeficiency virus-1 (HIV-1), the causative pathogen of acquired immune deficiency syndrome (AIDS) in humans, persists as a global health concern with an incidence rate of 1.7 million in 2019 and an estimated global prevalence of 38 million [1]. To counteract the global HIV-1 epidemic, combination antiretroviral therapy (cART) has been developed, and has demonstrated high levels of efficacy, safety and tolerability for people living with HIV (PLWH) [2]. cART treatment is typically composed of multiple antiretroviral drugs that target diverse steps of the HIV-1 replication cycle, including nucleoside reverse transcriptase inhibitors, non-nucleoside reverse transcriptase inhibitors, protease inhibitors, integrase inhibitors, and fusion/entry inhibitors [3]. cART treatment has been highly effective in reducing viral burden, ultimately resulting in prolonged life expectancy of PLWH $[2,4,5]$. However, despite the effectiveness of cART treatment, it is not curative. cART-treated HIV-1 patients exhibit viral latency, i.e., the ability of the virus to reside dormant within a cell, in the form of integrated viral DNA within long-lived tissue resident cells, and increased risk for chronic inflammation [6-12]. Whether this chronic inflammation is due to the treatment, residual inflammation, or viral latency is unknown. HIV-1 persistence in reservoirs is the major obstacle to an HIV-1 cure, as viral replication rapidly resumes after cART interruption. 
Major HIV-1 cellular reservoirs, within which HIV-1 latently persists, include differentiated memory and effector $\mathrm{CD}_{4}^{+} \mathrm{T}$-cell subsets, as well as tissue-resident resting myeloid cells $[6-8,13]$. These cells are not targeted by cART since they do not actively transcribe the virus, thereby resulting in survival of latent HIV-1 in the form of integrated viral DNA and permitting formation and maintenance of HIV-1 reservoirs [9]. Therefore, PLWH are required to take cART for life, while remaining at a higher risk than age-matched controls for mortalities and morbidities such as dementias, malignancies, and cardiovascular disease [11]. In order to circumvent these cART limitations, and to ultimately achieve HIV-1 cure, alternative combinatory HIV-1 therapeutic strategies are imperative.

Although cART was originally developed as a treatment for PLWH, recently it has also been adapted for pre-exposure prophylaxis (PrEP) for high-risk individuals including men who have sex with men (MSM), sex workers, and injection drug users. While PrEP has been demonstrated to be a successful preventative therapy, there are specific populations for which PrEP shows reduced efficacy, as reviewed in [14]. For instance, amongst young women with a high risk of HIV-1 infection, PrEP was demonstrated to be less effective in those with genital inflammation as compared to those without genital inflammation [15,16]. Hence, it is important to develop strategies that better protect groups with high risk for contracting HIV-1, and particularly for groups in which existing PrEP strategies show reduced efficacy.

\subsection{Innate Restriction Factors Are Natural Host Factors That Interfere with HIV-1 Replication}

Many efforts have been made to develop new drugs or combinational therapeutics together with cART [17-20]. One promising approach is to capitalize on antiviral restriction factors, which are innate host proteins that interfere with viral replication and therefore serve as a natural defense against HIV-1. A particular advantage of harnessing restriction factors for use as a prophylactic or therapeutic strategy against HIV-1 is the capacity of restriction factors to not only directly restrict HIV-1, but also to enhance innate and adaptive immune responses against the virus [21]. In general, restriction factors are interferon (IFN)-inducible, and their recognition of viral components often triggers innate immune activation which subsequently interferes with the virus replication cycle [22-26].

Although restriction factors have several shared characteristics, they utilize distinctive mechanisms to block specific steps of the viral replication cycle [21,27]. The HIV-1 replication cycle can be divided into eight main steps, each of which is a potential target for restriction factors. First, HIV-1 attaches and fuses with the host cell membrane, and the viral core, i.e., the viral capsid containing two single strands of RNA, the enzymes reverse transcriptase, integrase and protease, and additional variable viral proteins, is released into the cytoplasm. Subsequently, upon uncoating of the viral core, viral single stranded RNA is reverse transcribed into double stranded viral DNA, forming the pre-integration complex (PIC), which is imported into the nucleus. Upon integration of the viral DNA into the host DNA, HIV-1 utilizes the host transcription machinery to produce viral mRNA. Following nuclear export, these mRNAs serve as templates for viral proteins that are assembled into new viral particles at the cell surface. Finally, these viral particles bud and, upon cleavage by a viral protease, are released from the cell as mature infectious virus [28,29].

Several host restriction factors target the early stages of the viral replication cycle, prior to nuclear transport. For example, the constitutively expressed host restriction factor Serine Incorporator 5 protein (SERINC5), which inhibits the translocation of the viral capsid to the cytoplasm, restricts HIV-1 infection at an early stage of the replication cycle [30]. Similarly, several members of the interferon-induced transmembrane (IFITM) protein family, in particular IFITM2 and IFITM3, have been demonstrated to interfere with viral fusion [31,32]. In virus-producing cells, IFITMs are incorporated into daughter virions, which confers reduced infectivity $[31,33]$. Multiple restriction factors then target viral nucleic acids to prevent reverse transcription. For example, Apolipoprotein B mRNA Editing Enzyme Catalytic Subunit (ABOBEC) 3G accomplishes restriction by introducing guanosine-toadenosine hypermutation of the viral plus-strand DNA, leaving the virus incapable of 
effective reverse transcription [34]. Meanwhile, the dGTP-dependent deoxynucleotide triphosphohydrolase SAM domain and HD domain-containing protein 1 (SAMDH1) functions by starving the viral reverse transcriptase of intracellular dNTPs via hydrolyzation of these intracellular nucleic acids in non-cycling myeloid and $\mathrm{CD}^{+} \mathrm{T}$ cells [35-37]. Myxovirus resistance protein $\mathrm{B}(\mathrm{MxB}$; also known as MX2) is a late post-entry restriction factor, which interferes with nuclear import after reverse transcription to inhibit integration of proviral DNA, although it has also been suggested that MxB may additionally bind the HIV-1 capsid and inhibit uncoating earlier in the viral replication cycle [38,39].

Later in the virus replication cycle, Schlafen11 (SLFN11) then acts by selectively inhibiting expression of viral proteins. SLFN11 binds transfer RNA (tRNA) non-specifically, leading to preferential inhibition of viral protein synthesis due to the higher level of rare codons in viral genes as compared to host genes [40]. Subsequently, at the final stages of the virus replication cycle, additional HIV-1 restriction factors interfere with viral protein processing or function. The recently discovered interferon-inducible guanylate binding protein 5 (GBP5) targets a late stage of the viral replication cycle by interfering with processing of HIV-1 envelope glycoproteins, ultimately leading to assembly of noninfectious HIV-1 virions [41,42]. Membrane-associated RING (really interesting new gene)$\mathrm{CH}(\mathrm{MARCH})-2$ and MARCH8, which are both members of a larger E3 Ubiquitin ligase family, prevent the formation of infectious virions by targeting viral envelope proteins for degradation or intracellular retention [25,43]. Finally, tetherin, also known as BST-2 or CD317, accomplishes late-stage restriction of HIV-1 by preventing release of Vpu-deleted HIV-1 from restrictive cells, resulting in accumulation of mature HIV-1 particles on the cell surface $[23,44]$.

\subsection{TRIM5 $\alpha$ : From HIV-1 Restriction Factor to Induction of Antiviral Immunity}

Recent literature highlights that some restriction factors can be doubly functional upon sensing HIV-1, to both interfere with viral replication and also to act as sensors that initiate innate immune signaling pathways, which help to prevent further viral dissemination throughout the host [45-49].

The alpha isoform of tripartite motif (TRIM) protein 5 (TRIM $5 \alpha$ ) is one such restriction factor with both virus-restricting and -sensing properties. TRIM5 $\alpha$ was first described as a restriction factor upon discovery that it potently inhibited HIV-1 infection in rhesus macaques [50]. Already in the late 1990s, data emerged to demonstrate a species-specific block of HIV-1 prior to reverse transcription occurring in Old World Monkeys, but not humans [51-55]. However, the responsible species-specific dominant repressive factor targeting the incoming HIV-1 capsid remained undiscovered until 2004. Stremlau and colleagues identified TRIM $5 \alpha$ as the post-entry host factor potently restricting HIV-1 [50]. Expression of rhesus macaque TRIM5 $\alpha$ (rhTRIM5 $\alpha$ ) in HeLa cells led to significantly decreased HIV-1 infection as compared to HeLa cells containing empty vectors. However, although expression of rhTRIM5 $\alpha$ in HeLa cells efficiently blocked HIV-1 infection, simian immunodeficiency virus (SIV) was less restricted [50]. Furthermore, ectopic expression of the human TRIM $5 \alpha$ orthologue (huTRIM $5 \alpha$ ) failed to restrict HIV-1 as potently as rhTRIM $5 \alpha$. Taken together, these data led to the conceptualization of TRIM $5 \alpha$ as a speciesspecific HIV-1 restriction factor, with rhTRIM $5 \alpha$ but not huTRIM5 $\alpha$ efficiently restricting the virus [50]. In the following years, a wealth of literature has since focused on describing this TRIM $5 \alpha$-mediated mechanism of restriction [49,56-63].

It has since been demonstrated that rhTRIM $5 \alpha$ restricts HIV- 1 infection by forming hexagonal nets around incoming virus capsids and subsequently directing these TRIM $5 \alpha-$ HIV-1 complexes for degradation [56-60]. More recently, rhTRIM5 $\alpha$ was also reported to act as a pathogen recognition receptor (PRR) by sensing incoming retroviral capsids, and upregulating IFN responses as well as AP-1 and NF-KB-responsive inflammatory mediators [49,61-63]. Notably, recent literature indicates that huTRIM5 $\alpha$ is also a HIV-1 restriction factor; however, it functions via a distinct mechanism as compared to rhTRIM $5 \alpha$, and it likely operates in a cell-specific manner $[62,64,65]$. huTRIM5 $\alpha$ antiretroviral activ- 
ity is also regulated by supplementary host proteins, such as cell-specific receptors and chaperones $[64,66]$.

Here, we will explore the role of TRIM5 $\alpha$ in both HIV-1 restriction and antiviral immunity, with a focus on human TRIM $5 \alpha$. We will emphasize the relevancy of huTRIM $5 \alpha$ as a restriction factor, review its described restriction mechanisms and associated cellular degradation pathways, and discuss the role of TRIM $5 \alpha$ in informing the host innate immune system. Finally, we will outline potential applications of harnessing TRIM5 $\alpha-$ mediated antiviral pathways in innovative HIV-1 therapies.

\section{TRIM5 $\alpha$-Mediated HIV-1 Restriction Across Species}

\subsection{TRIM5 $\alpha$ of Old World Monkeys: The Case of Rhesus Macaques}

rhTRIM $5 \alpha$ is an approximately 500 -amino-acid-long protein that exists as either a free cytoplasmic protein or localized within highly mobile cytoplasmic clusters termed cytoplasmic bodies [50]. It is a member of the extensive TRIM (tripartite motif) protein family, so named for their inclusion of three characteristic domains: an amino-terminal RING (really interesting new gene) domain, a B-box, and a coiled-coil (CC) region [67]. The RING and B-box domains are connected via the linker region 1 (L1). This TRIM motif is connected to a carboxyl-terminal SPRY (also known as B30.2) domain via the flexible linker region 2 (L2). The SPRY domain, and in particular its variable sequence 1 (v1), one of three variable peptide sequences in the SPRY domain, mediates TRIM5 $\alpha$ interaction with retroviral capsids (Figure 1A) [68,69].

Studies conducted using purified rhTRIM $5 \alpha$ protein preparations or in human (HeLa) or canine (Cf2Th) cell lines stably transfected with rhTRIM5 $\alpha$ have found that the RING, SPRY, CC, and B-box domains of rhTRIM5 $\alpha$ all contribute to the HIV-1 restriction process. The CC and B-box domains facilitate the initial dimerization and subsequent multimerization of rhTRIM $5 \alpha$, promoting its aggregation into cytoplasmic bodies and, upon HIV-1 infection, formation of hexagonal rhTRIM5 $\alpha$ nets around target virus capsid proteins [58-60]. In vitro mutations of the B-box residue R121 inhibit the formation of hexagonal structures on the surface of HIV-1 capsid, and thereby abrogated rhTRIM $5 \alpha$-mediated HIV-1 restriction (Figure 1A) $[58,59,70]$. In addition, an I193A mutation within the CC-domain of a rhTRIM $5 \alpha$ fusion protein resulted in loss of restriction in HeLa cells and a slight instability of the rhTRIM5 $\alpha$ dimer [71]. Structural modeling indicated that residue I193 is likely important for the correct packaging of the CC/L2/SPRY domains, and that the I193A mutation may alter the positioning of the SPRY domain relative to the CC-domain, which is associated with defective binding to the viral capsid [71].

Cryogenic electron microscopy studies with purified rhTRIM5 $\alpha$ protein preparations have demonstrated that binding of the SPRY domain to the virus capsid promotes formation of hexagonal rhTRIM $5 \alpha$ nets that physically mirror the viral capsid surface lattice, thus compensating for the low affinity of the SPRY domain for the viral capsid by increasing binding avidity, and reinforcing rhTRIM5 $\alpha$ binding efficiency [60,72,73]. In HeLa and 293T cell lines transfected with rhTRIM5 $\alpha$, interaction of rhTRIM5 $\alpha$ with viral capsid cylinders leads to structural disruption of the HIV-1 capsid proteins, driving premature uncoating of the virus and thereby inhibiting viral genome translocation to the nucleus and retroviral integration $[50,74,75]$.

The E3 ubiquitin ligase activity of the RING domain of rhTRIM5 $\alpha$ is key in directing rhTRIM $5 \alpha$-mediated degradation of the HIV-1 capsid. Demonstrative of this, the R60A mutation within the rhTRIM5 $\alpha$ RING domain, which abolishes its E3 ubiquitin ligase activity, interferes with retroviral restriction (Figure 1A) [76,77]. The rhTRIM5 $\alpha$ RING domain normally directs the elongation of N-terminally anchored K63-linked ubiquitin chains to the viral capsid, which tags the incoming virus for destruction. These ubiquitintagged rhTRIM $5 \alpha$-HIV- 1 complexes are then directed to the proteasome for subsequent degradation $[56,78-80]$. 

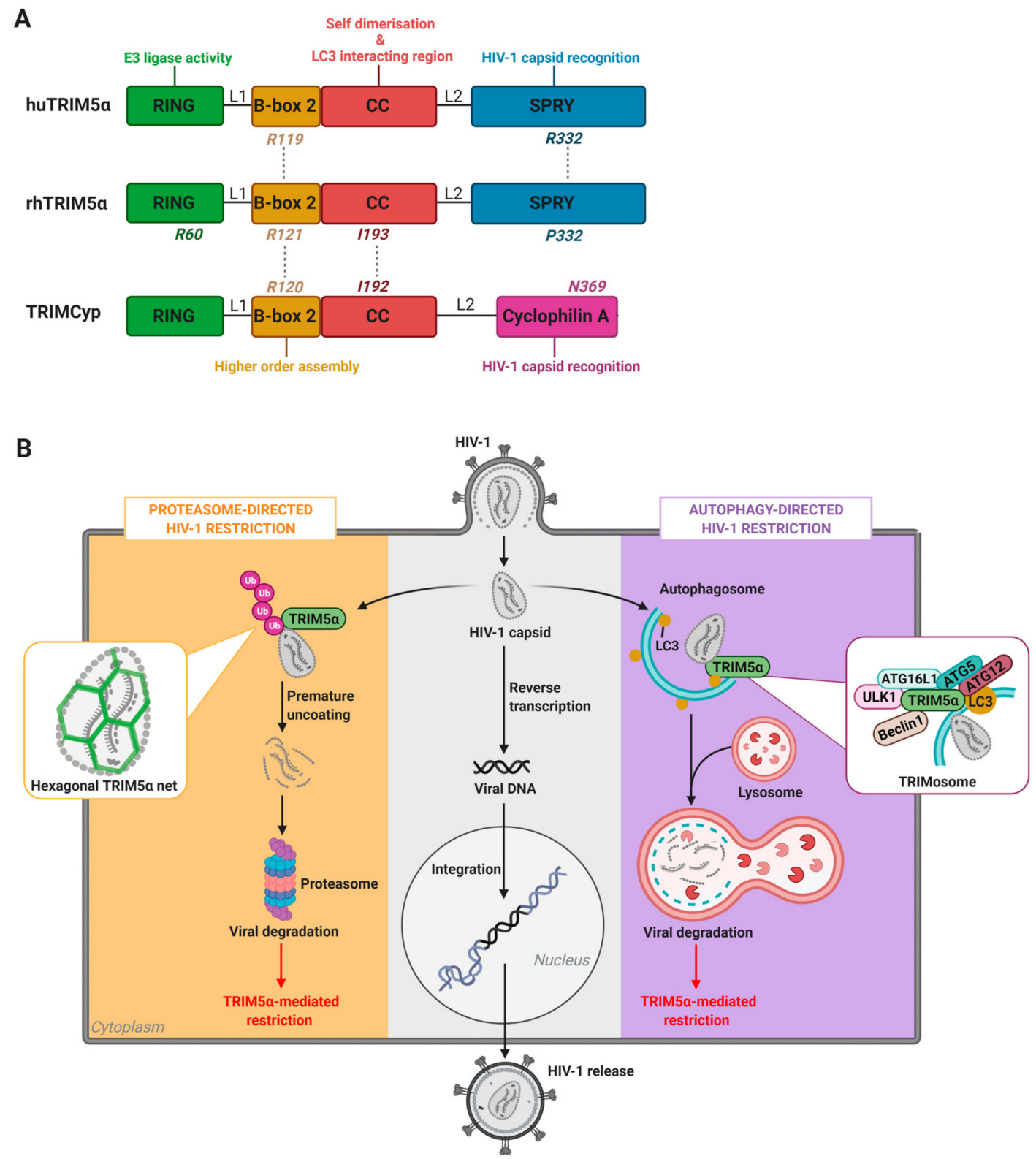

Figure 1. Structure and functions of TRIM5 $\alpha$. (A) Rhesus (rh)TRIM5 $\alpha$, human (hu)TRIM5 $\alpha$, and TRIMCyp protein domain organization and associated functions. Key amino acid residues impacting antiviral functions per protein domain are depicted. (B) Schematic overview of the main steps of HIV-1 virus replication cycle (center panel, in grey), and the proteasome-directed (left panel, in orange) and autophagy-directed (right panel, in purple) TRIM5 $\alpha$-mediated mechanisms of HIV-1 restriction. RING: really interesting new gene, CC: coiled-coil, LC3: microtubule-associated protein 1A/1B-light chain 3, ULK1: Unc-51 like autophagy activating kinase 1, ATG: autophagy related, Ub: ubiquitin, L1: linker 1, L2: linker 2.

It has been reported that proteasome inhibition with small-molecule inhibitor MG132 or deletion of the RING domain limits but does not completely abrogate rhTRIM $5 \alpha$ mediated HIV-1 restriction [78,81]. Proteasome inhibition or introduction of RING domain mutations C15A or C18A in rhTRIM5 $\alpha$ alters the intracellular localization of rhTRIM5 $\alpha$, causing it to accumulate in relatively large cytoplasmic or (peri)nuclear bodies, respectively, and resulting in decreased availability of rhTRIM5 $\alpha$ to restrict HIV-1 [78,81]. Furthermore, disrupting proteasome function permitted the generation of HIV-1 late reverse transcription products, although infection with a single cycle R7 $\triangle$ EnvGFP reporter HIV-1 virus, as measured by $\mathrm{GFP}^{+}$cells, remained impaired. Taken together, these data underline that rhTRIM $5 \alpha$ acts soon after entry of the retroviral capsid into the cytoplasm, prior to reverse 
transcription, and together with the proteasome system prevents reverse transcription of HIV-1 and drives proteasomal degradation of rhTRIM5 $\alpha$-HIV-1 complexes.

\subsection{TRIM5 $\alpha$ of New World Monkeys: The Case of TRIMCyp}

It is common amongst Old World monkeys such as Rhesus macaques to exhibit TRIM $5 \alpha$-mediated post-entry restriction of HIV-1, but this phenotype is less common amongst New World monkeys. Owl monkeys specifically exhibit a distinct pattern of HIV-1 restriction not detected in the other New World monkeys such as squirrel monkeys, golden-headed lion tamarins, or black-tailed marmosets [51]. The protein responsible for HIV-1 restriction in owl monkeys was identified to be a fusion protein in which the SPRY domain of TRIM5 $\alpha$ has been replaced by the coding sequence of Cyclophilin A (CypA) due to a historical Long Interspersed Element 1 (LINE-1) retrotransposition event [82]. CypA is a host chaperone prolyl isomerase that has interacted with prehistoric lentivirus capsids related to HIV-1 throughout evolution via an exposed peptide loop on the viral capsid lattice $[83,84]$. The resultant fusion protein, termed TRIMCyp, is a potent inhibitor of lentiviruses, including of HIV-1 by owl monkeys $[60,82,85,86]$. In addition, CypA has been implicated in MxB-mediated HIV-1 restriction, although the molecular details of this interaction are not yet fully elucidated $[87,88]$.

Owl monkey TRIMCyp-mediated HIV-1 restriction relies on multimeric binding to incoming virus, with the CypA domain (replacing the SPRY domain of rhTRIM5 $\alpha$ ) binding the HIV-1 capsid [89,90]. Recent studies have highlighted that, similar to $\operatorname{rhTRIM} 5 \alpha$, the TRIMCyp CC and B-box domains facilitate its dimerization and subsequent multimerization, thereby promoting aggregation into cytoplasmic bodies and, upon HIV-1 infection, formation of hexagonal TRIMCyp nets around target virus capsid proteins [60,91]. Higherorder assembly of TRIMCyp may serve an analogous function of coupling capsid binding and ubiquitination to promote HIV-1 degradation, as with rhTRIM $5 \alpha$.

Like rhTRIM $5 \alpha$, mutating amino acid residue R120 within the TRIMCyp B-box domain abrogates HIV-1 restriction by TRIMCyp (Figure 1A) [70]. In contrast to the rhesus orthologue, mutation of the TRIMCyp CC-domain residue I192 did not result in the abrogation of HIV-1 restriction [71].

With regard to capsid binding, N369 within the CypA domain of TRIMCyp is a key residue for HIV-1 capsid recognition (Figure 1A) [92]. Correspondingly, treatment of HIV1-GFP-infected HeLa cells with cyclosporine A, which binds the CypA domain, completely abrogated TRIMCyp restriction, indicating that viral capsid binding by the CypA domain is essential for the TRIMCyp's HIV-1 inhibitory function [91,93].

\subsection{Human TRIM5 $\alpha$}

Akin to its rhesus macaque orthologue, the huTRIM $5 \alpha$ structure contains the characteristic RING, B-box, CC region, and SPRY domains. Exogenous huTRIM5 $\alpha$ is able to restrict some lentiviruses, such as N-tropic murine leukemia viruses (N-MLV) in human and mouse cell lines [94]. Unlike rhTRIM5 $\alpha$, huTRIM5 $\alpha$ does not efficiently restrict HIV-1 in cell lines [50]. For example, huTRIM5 $\alpha$ stably expressed in HeLa cells only slightly inhibits HIV-1-GFP (recombinant HIV-1 expressing GFP pseudotyped with VSV-G glycoprotein) when compared to HeLa-cells expressing rhTRIM5 $\alpha$ [50]. Likewise, huTRIM5 $\alpha$ expressed in the feline cell line CRFK weakly restricts HIV-1, while rhTRIM5a completely blocks infection [95]. It has previously been suggested that the differing patterns of retrovirus restriction by rhTRIM $5 \alpha$ versus huTRIM $5 \alpha$ observed in cell lines is due to variation in the SPRY v1 sequence between the two orthologues, in line with the long-standing belief that HIV-1 restriction by rhTRIM $5 \alpha$ is species-specific $[96,97]$.

The apparent decreased ability of huTRIM $5 \alpha$ to restrict HIV-1 in cell lines has been associated to low affinity for the viral core and instability of the protein [98]. In support of this, a single amino acid substitution on position 332 from arginine to proline (R322P), mimicking the sequence in rhTRIM $5 \alpha$, conferred the ability of huTRIM5 $\alpha$ to restrict HIV- 1 , though ten times less efficient than rhTRIM5 $\alpha$ [99]. Furthermore, a R332/R335 double 
mutation in the SPRY domain provided HIV-1 resistance similar to rhTRIM5 $\alpha$ in a T-cell line (SUP-T1) and in primary human T-cells $[97,98]$. In addition, stabilization of huTRIM5 $\alpha$ via fusion to mCherry resulted in robust restriction of HIV-1 strains SF162 and BK132 [98]. This indicated that huTRIM $5 \alpha$ is able to bind HIV- 1 but that the increased degradation of the human orthologue as compared to rhTRIM $5 \alpha$ hampers the HIV-1 restrictive capabilities of huTRIM5 $\alpha$. Furthermore, it has also been demonstrated that the huTRIM5 $\alpha$ B-box residue R119, similar to its orthologues rhTRIM5 $\alpha$ (R121) and TRIMCyp (R120), is essential for hexagonal structure formation and viral restriction [70]. huTRIM5 $\alpha$ R119E and R119D mutants lost antiretroviral activity against non-human viruses such as N-MLV (Figure 1A) [70].

Notably, Ribeiro and colleagues were the first to show that huTRIM5 $\alpha$ is a potent HIV1 restriction factor in specific primary human cells [64]. However, it functions via a distinct mechanism to rhTRIM5 $\alpha$, which relies on HIV-1 uptake via specific cell surface receptors and on an alternative cellular degradation system in human primary immune cells [64]. Recent literature support these findings and further demonstrated the capacity of huTRIM5 $\alpha$ to bind the HIV-1 capsid and efficiently restrict HIV-1 infection in human primary immune cells using alternative host proteins and cellular degradations pathways [65,66,100].

\section{The Nexus Between TRIM5 $\alpha$ Antiviral Functions and Host Degradation Pathways}

Abnormal, aggregated, or non-self-cytosolic material is typically degraded by one of two host degradative pathways: the proteasome system or the autophagy pathway [101,102]. Both systems are capable of degrading ubiquitinated intracellular substrates. Differential ubiquitination and the oligomeric state of the receptors that recognize the substrate destined for degradation determine which degradative pathway the substrate will take. Monomeric proteasome receptors have high affinity for ubiquitin and therefore preferably bind soluble substrates. On the other hand, substrate aggregation favors autophagic degradation due to the high avidity of oligomeric receptors [101,103].

The proteasomal degradation system relies on three categories of ubiquitin-related enzymes, namely, E1 ubiquitin-activating enzymes, E2 ubiquitin-conjugating enzymes, and E3 ubiquitin ligases [104]. First, an E1 ubiquitin-activating enzyme binds ubiquitin molecules and transfers the molecule to an E2 ubiquitin-conjugating enzyme. Then, the E2 ubiquitin-conjugating enzyme, together with the bound ubiquitin, interacts with the substrate-bound E3 ubiquitin ligase [105]. RING-type E3 ubiquitin ligases, so named for their inclusion of a RING domain, as does TRIM5 $\alpha$, determine the fates of cytosolic target proteins by recognizing and transferring ubiquitin to target proteins. Repeated interactions of these three enzymes results in polyubiquitination of the substrate, generally forming a so-called K48 ubiquitin chain, i.e., a polymeric ubiquitin chain formed via linking of the K48 residues of multiple ubiquitin monomers, thereby earmarking the substrate for degradation via the $26 S$ proteasome $[106,107]$. The $26 S$ proteasome consists of a $20 S$ proteolytic core particle that is flanked by two $19 \mathrm{~S}$ lid particles. Upon recognition of the ubiquitinated substrate by the 195 lid, the substrate is translocated into the barrel shape of the proteasome and cleaved by proteases in the catalytic sites of the 20S core $[105,108]$. Proteasomal degradation of HIV-1 proteins may have both proviral and antiviral roles as reviewed in [109], including rhTRIM5a-mediated HIV-1 degradation.

Autophagy is a process in which specialized double-membrane intracellular vesicles form to engulf cytosolic cargo such as viral components and target them for lysosomal degradation [110]. Thus, autophagy functions as an innate immune defense mechanism against intracellular pathogens. Generally, larger cytoplasmic cargo that exceeds the spatial capacity of proteasomes is directed to autophagy-mediated degradation [111]. The initiation of the autophagosomal membrane, which sequesters cytosolic cargo, is under control of several proteins, including ULK1 and Beclin 1 [112,113]. After formation of the autophagosome, which requires the involvement and cooperation of multiple proteins including autophagy-related (ATG) proteins, further elongation of the nascent autophagic membrane is dependent on ubiquitin-like conjugation complexes. The ubiquitin-like protein ATG12 forms a complex with ATG5 and ATG16L1, that together with the proteins ATG4, ATG7, 
and ATG3, processes and lipidates the ubiquitin-like microtubule-associated protein 1 light chain 3 (LC3) into LC3-II [114]. LC3-II is subsequently conjugated to membrane-embedded phosphatidylethanolamine (PE) in the inner and outer membrane of the autophagosome, via the E3 ligase activity of the ATG16L1/ATG12/ATG5 complex, and directs sequestering of cargo including an LC3-interacting region (LIR) [115-117]. Additionally, LC3-11 is essential for elongation and closure of the phagophore membrane to form the autophagosome [118]. Subsequently, mature autophagosomes fuse with lysosomes resulting in the formation of autolysosomes, within which the cytoplasmic cargo is degraded due to acidification of the autolysosomal lumen and the activity of lysosomal hydrolases [119]. This continual process of degradation can be referred to as autophagy flux [120].

Selective autophagy, which can be differentiated from bulk autophagy by its specific targeting of cytoplasmic components including protein aggregates and intracellular pathogens for degradation, is dependent on interactions between autophagy receptors, LC3, and cargo [121,122]. Autophagy receptors such as p62 contain a ubiquitin binding site as well as a LIR motif. Thus, these receptors simultaneously bind to poly-ubiquitinated cytoplasmic cargo, and to LC3-II that coats the autophagosomal membrane, thereby directly targeting cargo into autophagosomes [121,123]. Notably, TRIM5 $\alpha$ has been demonstrated to include a LIR motif in its CC domain, and to bind p62 [26,124]. Additionally, TRIM proteins can induce a similar but distinct process termed precision autophagy. Here, autophagy can be induced by TRIM proteins bound to cargo without requiring ubiquitination or other protein tags [125].

\subsection{Cellular Degradation Pathways in HIV-1 Restriction: The Proteasome Versus Autophagy}

The main mechanism underlying the restrictive capacity of TRIM $5 \alpha$ was long suggested to be early disruption of the HIV-1 capsid and, subsequently, capsid degradation via the proteasome system (Figure 1B) [56,78]. rhTRIM5 $\alpha$-mediated, proteasome-dependent HIV-1 restriction was originally discovered upon transduction of rhTRIM5 $\alpha$ in HeLa cells incubated with single round recombinant GFP-reporter HIV-1 pseudotyped with VSVG [50]. Expression of rhTRIM5 $\alpha$ in these cells led to significantly decreased infection rates as compared to inoculation of parental HeLa cells. The E3 ubiquitin ligase activity of the rhTRIM $5 \alpha$ RING domain facilitates proteasome-dependent HIV-1 restriction. Together with the RING domain, the B-box 2 and CC domains promote formation of higher order complexes of rhTRIM $5 \alpha$, which enhances the interaction of the SPRY domain with the viral capsid of HIV-1, as described in Section 2.1 in more detail [126]. Subsequently, the RING domain initiates polyubiquitination of rhTRIM $5 \alpha$-HIV-1 complexes located within cytoplasmic bodies [127].

Co-localization of rhTRIM $5 \alpha$ with the proteasomal system has also been demonstrated in human 293T and HeLa cell lines stably expressing rhTRIM5 $\alpha$ [57]. Notably, the immunoproteasome has recently been implicated in IFN-facilitated, huTRIM $5 \alpha$-mediated HIV-1 restriction in $\mathrm{CD}^{+} \mathrm{T}$ cells, as is discussed in more detail in Section $4.3[65,100]$. However, there have been conflicting reports with regard to the significance of proteasomal activity in rhTRIM5 $\alpha$-mediated HIV-1 restriction. rhTRIM5 $\alpha$ and owl monkey TRIMCyp are still active in presence of proteasome inhibitors or in cell lines lacking active ubiquitin-activating E1 enzymes $[56,128]$. Additional studies have indicated that although proteasome inhibition with MG132 prevents rhTRIM5 $\alpha$-mediated capsid disassembly and restores HIV- 1 reverse transcription in HeLa cells, HIV-1 infection is still impaired [56,78]. This suggests either a two-phase restriction mechanism of $\operatorname{rhTRIM} 5 \alpha$, involving first a disruption in passage of the viral genome to the nucleus and secondly targeting of rhTRIM5 $\alpha$-HIV-1 complexes for degradation, or the involvement of additional degradation pathways [24,78]. In support of the latter possibility, it has recently been demonstrated that both rhTRIM5 $\alpha$ and huTRIM $5 \alpha$ can act as platforms for assembly of autophagy regulating proteins, indicating that, similar to other TRIM proteins, TRIM $5 \alpha$ can induce precision autophagy pathways $[64,124,129]$. 


\subsection{TRIM-Mediated Precision Autophagy}

As briefly described above, TRIM proteins have been shown to mediate an additional form of autophagy, termed precision autophagy $[125,129,130]$. Precision autophagy is distinct from selective autophagy, which typically requires at least two different host proteins - one for target recognition and a second for promoting assembly of the autophagy machinery $[64,125,129,131,132]$. In contrast, during TRIM-mediated precision autophagy, TRIM proteins play dual roles: they both directly recognize target cargo and assemble the proteins required for autophagy, including initiator proteins (e.g., ULK1 and Beclin 1), elongation proteins (e.g., ATG5), and LC3.

In HeLa cells, both huTRIM $5 \alpha$ and rhTRIM5 $\alpha$ were demonstrated to interact with LC3 via the helical LIR within their CC domains [124,129]. Furthermore, huTRIM5 $\alpha$ and rhTRIM $5 \alpha$ were demonstrated to interact with ULK1 via their SPRY domains, thereby inducing autophagy [129]. In addition, knockdown of autophagy proteins Beclin 1 and p62 in rhesus FRhK-4 and rhesus primary $\mathrm{CD}^{+} \mathrm{T}$ cells has been demonstrated to affect, although not abrogate, rhTRIM $5 \alpha$-mediated restriction of HIV-1 and VSVG-pseudotyped HIV-1 $[129,133]$. Notably, knockdown of ATG16L1 in a rhTRIM5 $\alpha$-transduced U87 cell line also slightly reduced HIV-1 restriction by rhTRIM5 $\alpha$ [64]. Furthermore, exogenous rhTRIM $5 \alpha$ was recently demonstrated to be localized within different autophagy vesicles in HeLa cells, although in a second study, depletion of ATG5 and Beclin 1 in HeLa cells transduced with rhTRIM5 $\alpha$ did not result in significantly decreased restriction of VSV-g pseudotyped HIV-1 reporter virus infection [133,134]. Taken together, these results indicate that rhTRIM5 $\alpha$ can act as a platform for the assembly of active autophagy components and formation of autophagy vesicles upon sensing the HIV-1 capsid in both human and macaque cell lines, although the autophagy pathway, in contrast to proteasome system, appears to have minimal importance in the rhTRIM $5 \alpha$-mediated HIV-1 restriction mechanism.

Strikingly, in specific primary human cell subsets, huTRIM5 $\alpha$ has been demonstrated to not only act as an efficient scaffolding platform for autophagy regulators upon HIV1 sensing, but also to restrict HIV-1 via an autophagy-dependent mechanism. These findings underline a pivotal role for autophagy in HIV-1 infection of human primary cells [64]. Upon recognizing its cargo, huTRIM5 $\alpha$ has been shown to form complexes with ATG16L1 and ATG5, thereby promoting degradation of its bound cargo via precision autophagy as illustrated in Figure 1B [64]. Silencing of ATG5 or ATG16L1 in primary human Langerhans cells (LCs) resulted in increased HIV-1 integration, underlining the role of autophagy in huTRIM $5 \alpha$-mediated HIV-1 restriction [64]. Although the ability of TRIM $5 \alpha$ to form scaffolding platforms for assembly of autophagy regulating proteins is conserved throughout primate evolution, autophagy primarily plays a pivotal role in huTRIM $5 \alpha$ autophagy-mediated HIV-1 restriction, unlike the apparent lesser role of autophagy in HIV-1 restriction by its rhesus orthologue $[64,125,135]$.

\subsection{Human TRIM5 $\alpha$ Restricts HIV-1 in Epithelial Langerhans Cells}

In the late 2000s, it was discovered that primary human LCs, a subset of Dendritic cells (DCs) that reside in mucosal epithelium, are a natural barrier to HIV-1 infection (Figure 2A,B) $[64,136,137]$. Together with subepithelial DCs, epithelial LCs are among the first immune cells to come in contact with HIV-1 during sexual transmission [138,139]. The HIV-1 receptor for LCs is the cell-specific C-type lectin Langerin, which allows LCs to efficiently capture HIV-1 from the extracellular milieu [136,140,141]. Upon capture of HIV-1, Langerin directs internalization of HIV-1 virions to Birbeck granules, which are LC-specific organelles that play a key role in LC-specific restriction of HIV-1 $[136,137]$. However, the mechanism of HIV-1 degradation after internalization into Birbeck granules in LCs remained a mystery for nearly a decade. The restriction was not facilitated by the proteasomal system, as demonstrated by MG132 not interfering with HIV-1 restriction [64]. Notably, HIV-1 restriction by Langerin occurs after HIV-1 fusion but before integration of viral DNA into the host genome [142]. It has been reported that the post-entry restriction 
factor SAMHD1 is ineffective in LCs, indicating that another post-entry antiviral factor must be of importance $[143,144]$.

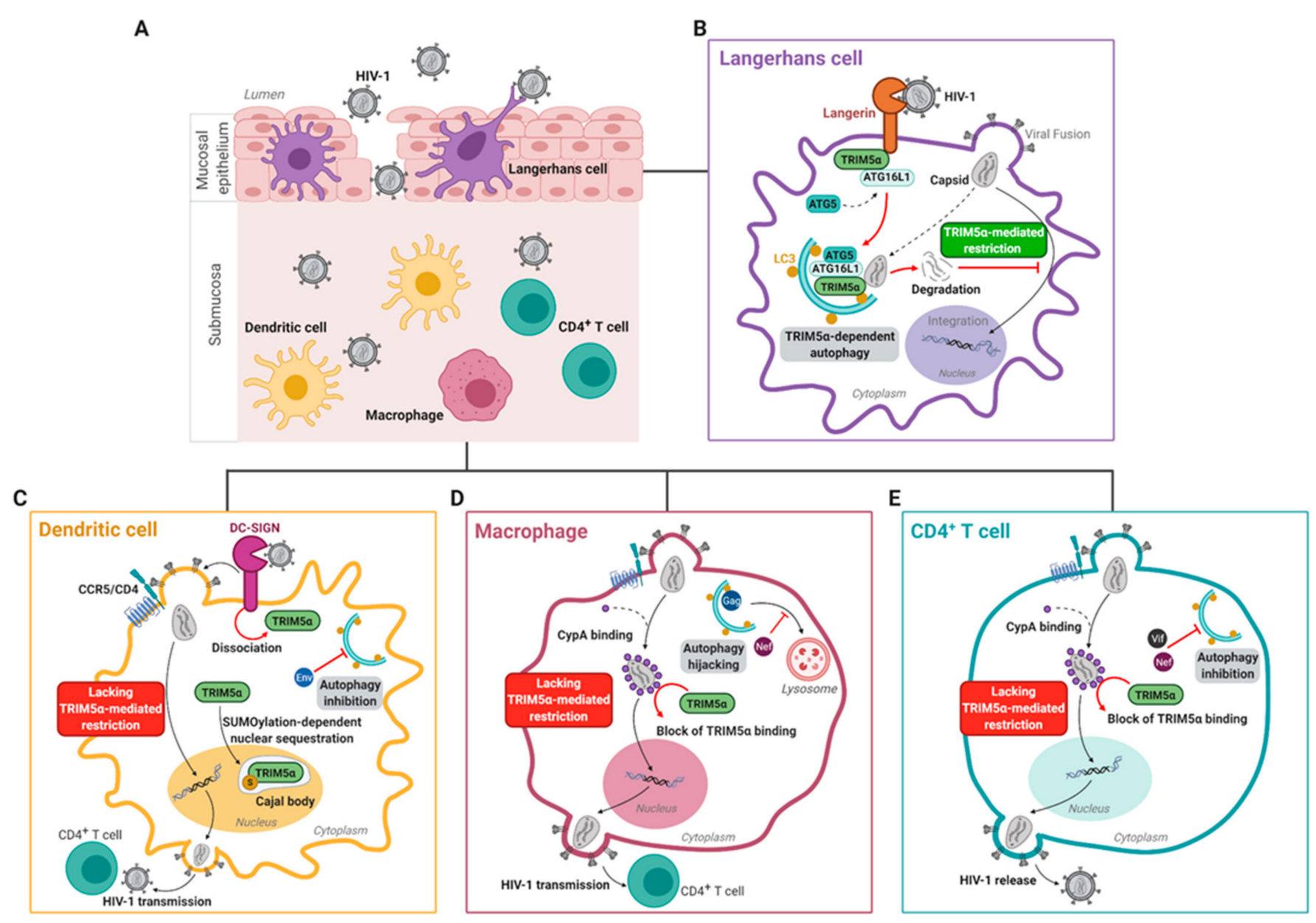

Figure 2. Cell-specific TRIM5 $\alpha$-mediated HIV-1 restriction. Langerhans cells, which reside within the mucosal epithelium (A), are able to restrict HIV-1 infection via a TRIM $5 \alpha$-mediated mechanism (B). At steady-state, the Langerhans cellspecific receptor Langerin is in association with a TRIM5 $\alpha$-ATG16L1 complex. Binding of Langerin to HIV-1 results in the internalization of the virus. Upon viral fusion, human TRIM $5 \alpha$ mediates recruitment of ATG5 to form the TRIM $5 \alpha-$ ATG16L1-ATG5-HIV-1p24 capsid complex, which promotes autophagosome formation and subsequent degradation of the viral capsid, thereby preventing HIV-1 infection and transmission by human Langerhans cells. Contrastingly, human and non-human primate dendritic cells, which reside within the submucosa (A), lack efficient TRIM $5 \alpha$-mediated retroviral restriction (C). Submucosal dendritic cells capture HIV-1 via the receptor DC-SIGN, which promotes productive HIV-1 infection of dendritic cells. Upon binding of HIV-1 to dendritic cells, TRIM5 $\alpha$ dissociates from the DC-SIGN signalosome, and TRIM $5 \alpha$ is trapped in nuclear Cajal bodies via a SUMOylation-dependent manner, thereby preventing cytosolic TRIM5 $\alpha$ from forming a complex with the incoming viral capsid. In addition, autophagy is inhibited by the HIV-1 protein Env. Altogether, this results in HIV-1 escape from human TRIM5 $\alpha$ /autophagy-mediated HIV-1 restriction mechanisms. (D) Upon fusion of the viral capsid with the macrophage membrane, the host protein CypA readily binds the incoming HIV-1 capsid. CypA coating of the capsid blocks the interaction of human TRIM5 $\alpha$ with the viral capsid, and thereby prevents human TRIM $5 \alpha$-mediated restriction in macrophages. In macrophages, HIV-1 hijacks the early stages of the autophagy pathway for HIV-1 Gag processing. In addition, HIV-1 Nef inhibits the late degradative stages of autophagy thereby preventing lysosomal viral degradation. (E) The autophagy machinery is also downregulated in CD4 ${ }^{+}$T cells by the HIV-1 proteins Vif and Nef. HIV-1 can thereby integrate into the host genome in CD4 ${ }^{+} \mathrm{T}$ cells unhindered, to replicate and be released. Similar to macrophages, upon fusion of the viral capsid with the CD4 ${ }^{+} \mathrm{T}$ cell membrane, CypA binds the incoming HIV-1 capsid, preventing human TRIM5 $\alpha$-mediated restriction in $\mathrm{CD}^{+} \mathrm{T}$ cells. S: small ubiquitin-like modifier (SUMO), CypA: Cyclophilin A. 
Notably, in primary human LCs, CD4 ${ }^{+} \mathrm{CCR} 5^{+}$Langerin $^{+} \mathrm{U} 87$ cells, and MUTZ3-derived LCs infected with CXCR4- or CCR5- tropic viruses, RNAi-based silencing of huTRIM5 $\alpha$ resulted in increased HIV-1 integration into the host genome, increased productive infection, and enhanced HIV-1 transmission to $\mathrm{CD}^{+} \mathrm{T}$ cells [64]. huTRIM5 $\alpha$ mediates the assembly of an autophagy-activating scaffold to Langerin, which targets the HIV-1 capsid for autophagic degradation and prevents infection of LCs. We were therefore the first to show that huTRIM $5 \alpha$ is a potent HIV- 1 restriction factor in LCs. At steady-state, Langerin associates with the LSP-1-TRIM5 $\alpha$-ATG16L1 complex. Capture of HIV-1 by Langerin then targets internalization of the incoming virus into Birbeck granules. Upon viral fusion, huTRIM $5 \alpha$ mediates recruitment of ATG5 to the TRIM5 $\alpha$-ATG16L1-HIV-1p24 capsid complex, which promotes induction of autophagosome formation and subsequently targeting of HIV-1 capsid complexes into autophagy vesicles for lysosomal degradation (Figure 2B) $[64,145,146]$.

Furthermore, silencing of either huTRIM $5 \alpha$ or the autophagy regulating proteins ATG5 or ATG16L1 in primary human LCs and $\mathrm{CD} 4^{+} \mathrm{CCR} 5^{+}$Langerin ${ }^{+} \mathrm{U} 87$ cells abrogated HIV-1 restriction, while treatment with the autophagy-enhancing drug rapamycin decreased HIV-1 integration in primary human LCs [64]. CD4 ${ }^{+}$CCR $5^{+} \mathrm{U} 87$ cells overexpressing huTRIM $5 \alpha$ demonstrated increases in both ATG5 recruitment to ATG16L1-TRIM5 $\alpha$ complexes, and in LC3-II levels in the presence of bafilomycin, indicating that huTRIM5 $\alpha$ overexpression boosts autophagy levels [64]. Altogether, these data show that HIV-1 degradation in primary human LCs occurs via a TRIM $5 \alpha$-directed autophagy restriction mechanism.

Notably, huTRIM $5 \alpha$-mediated HIV-1 restriction is strongly dependent on the viral uptake pathway. Although huTRIM5 $\alpha$ efficiently restricts HIV-1 in primary human LCs, it does not restrict VSV-G-pseudotyped HIV-1, which bypasses Langerin in both primary LCs as well as $\mathrm{CD}^{+}{ }^{+} \mathrm{CCR} 5^{+}$Langerin ${ }^{+} \mathrm{U} 87$ cells $[64,147]$. In contrast, rhTRIM5 $\alpha$ efficiently restricts both HIV-1 and VSV-G-pseudotyped HIV-1 [50,64,75].

Primary human DCs, which do not express Langerin but rather the C-type lectin receptor DC-SIGN, are more permissive to HIV-1 (Figure 2C) [64,136,148-150]. Unlike Langerin, DC-SIGN facilitates HIV-1 infection of and transmission by DCs, and silencing huTRIM5 $\alpha$ in DC-SIGN ${ }^{+}$DCs did not affect levels of HIV-1 integration nor infection [64,151,152]. Whereas huTRIM $5 \alpha$ remains in association with the Langerin signalosome upon HIV-1 capture by Langerin in LCs, binding of HIV-1 to DC-SIGN in DCs leads to disassociation of huTRIM $5 \alpha$ from the DC-SIGN signalosome, possibly contributing to the lack of huTRIM $5 \alpha-$ mediated HIV-1 restriction in submucosal DCs (Figure 2B,C) [64]. Furthermore, HIV-1 rapidly downregulates autophagy in DCs, which may represent an additional strategy evolved by the virus to evade autophagy-mediated degradation $[64,153]$. Thus, these data outline a novel autophagy- and receptor- controlled huTRIM5 $\alpha$ restriction mechanism, dictating protection or infection of human DC subsets.

The restrictive capacity of LCs is impaired with specific HIV-1 variants, and during conditions such as tissue immune activation and co-infections, resulting in increased susceptibility to HIV-1. For example, some Transmitted/Founder HIV-1 strains are able to escape Langerin-dependent huTRIM5 $\alpha$-mediated HIV-1 restriction in LCs [154]. Furthermore, co-infections, for example, with additional sexually transmitted infections such as gonorrhea and candidiasis, also increase LC susceptibility to HIV-1 infection and transmission [155-157]. Lastly, activation of LCs by tumour necrosis factor (TNF) can also promote HIV-1 transmission from LCs to T-cells [155]

\section{HIV-1 Escapes huTRIM5 $\alpha$-Mediated Restriction in Submucosal DC-SIGN ${ }^{+}$ Dendritic Cells and $\mathrm{CD}^{+}{ }^{+} \mathrm{T}$ Cells}

\subsection{Submucosal Dendritic Cells}

Although huTRIM5 $\alpha$ has been demonstrated to restrict HIV-1 in an autophagydependent manner in primary human LCs, several groups have independently shown that huTRIM $5 \alpha$ is unable to restrict HIV-1 in other primary targets such as submucosal DCs $[64,153]$. An important receptor for HIV-1 transmission is the highly expressed surface 
receptor DC-SIGN [152]. Normally, upon binding to a ligand, DC-SIGN facilitates receptormediated endocytosis to initiate antigen-processing [158]. In addition, DC-SIGN facilitates interaction of DCs with $\mathrm{CD}^{+}$T-cells via the immunological synapse [152]. Several studies have also shown that submucosal DCs are able to facilitate HIV-1 transmission via a mechanism termed trans-infection $[152,159,160]$. During this mechanism, DCs capture the virus and transmit it to $\mathrm{CD} 4^{+} \mathrm{T}$-cells via a virological synapse, without replication of the virus within the DCs. Several independent studies have also reported productive HIV-1 infection of submucosal DCs, with active replication prior to transmission to other cells (termed cis-infection), although productive infection of DCs compared to CD4 ${ }^{+} \mathrm{T}$-cells is 10- to 100 -fold lower $[150,151,161]$. In the case of productive infection, DC-SIGN strongly binds the HIV-1 envelope glycoprotein gp120 and together with other PRRs is essential for viral replication in DCs $[151,162,163]$. In particular, DC-SIGN-mediated signaling, which is induced upon binding of the HIV-1 envelope glycoprotein gp120, is necessary for eventual generation of full-length virus transcripts [151]. In addition, HIV-1 envelope protein Env activates mammalian target of rapamycin (mTOR), thereby downregulating autophagy, which prevents autophagy-mediated viral degradation. In support of this, treatment with the mTOR inhibitors everolimus or rapamycin results in induction of autophagy, leading to a reduction in productive HIV-1 infection of tissue-derived DCs, and a decrease in transmission of HIV-1 by human DCs to CD4 ${ }^{+}$T-cells $[153,164]$.

Notably, at steady-state conditions, huTRIM $5 \alpha$ forms a complex with DC-SIGN, in a manner similar to that with Langerin as described in Section 3.3 [64]. However, upon binding of HIV-1 to DC-SIGN, huTRIM5 $\alpha$ dissociated from the DC-SIGN signalosome [64] (Figure 2C). In concurrence with this data, silencing of huTRIM5 $\alpha$ in DC-SIGN ${ }^{+}$DCs had no effect on HIV-1 integration or infection [64]. This highlights that multiple C-type lectin receptors, including DC-SIGN and Langerin, can form complexes with huTRIM5 $\alpha$, but that the HIV-1 restriction properties of huTRIM $5 \alpha$ are cell-specific and receptor-dependent.

Recently, new light was shed on the lack of HIV-1 restriction by huTRIM $5 \alpha$ in primary human monocyte-derived DCs $[62,144]$. In human DCs, huTRIM5 $\alpha$ is sequestered in Cajal bodies, a subset of membrane-less nuclear bodies consisting mostly of proteins and RNA, and other nuclear bodies via a small ubiquitin-like modifier (SUMO)ylation-dependent manner. Nuclear sequestration of huTRIM $5 \alpha$ makes room for innate immune sensing of retroviral genetic material by the DNA sensor cGAS in the cytosol, leading to potent induction of type I IFN responses that are key for promoting an antiviral state [62,144]. Strikingly, overexpression of huTRIM5 $\alpha$ in human DCs, or treatment with an inhibitor of SUMOylation, restored cytoplasmic huTRIM5 $\alpha$ expression and efficient huTRIM $5 \alpha-$ mediated HIV-1 restriction [62]. These results suggest the potentiality of huTRIM5 $\alpha$ to restrict HIV-1 in other DC subsets in addition to LCs.

Furthermore, a recent study demonstrated the potential role for CypA in abrogating huTRIM $5 \alpha$-mediated HIV-1 restriction in DCs [165]. Infection of primary human monocytederived DCs with single round VSV-G pseudotyped HIV-1 viruses bearing capsid mutation P90A, which prevents CypA from interacting with the capsid, was less efficient as compared to infection with viruses lacking the P90A mutation [66,166,167]. HIV-1 infection by HIV-1 P90A was restored upon depletion of huTRIM5 $\alpha$ in the DCs, which further highlights the capacity of huTRIM5 $\alpha$ to inhibit HIV-1 in DCs [165]. It is important to note here that VSVG-pseudotyped HIV-1 largely bypasses the DC-SIGN uptake route, and that the observed huTRIM5 $\alpha$-mediated restriction of VSV-G pseudotyped HIV-1 P90A in DCs upon CypA depletion is yet to be confirmed with HIV-1 bearing the viral glycoprotein gp120 [165,168].

Notably, it was also recently demonstrated that rhTRIM5 $\alpha$ does not restrict HIV- 1 in primary rhesus macaque monocyte-derived DCs, unlike in other rhesus macaque primary cells or cell lines, or in human cell lines ectopically expressing rhTRIM5 $\alpha[50,169]$. Rather, rhTRIM $5 \alpha$ was SUMOylated and sequestered in the nucleus of rhesus macaque DCs following the same mechanism described in human DCs. Strikingly, this lack of restriction by rhTRIM5 $\alpha$ was also demonstrated in cynomolgus and pigtailed macaque DCs, as well 
as in African green monkey DCs, indicating that lack of TRIM5 $\alpha$-mediated restriction is prevalent in humans and other primate DCs [62].

This lack of TRIM $5 \alpha$-mediated restriction in DCs is thus conserved throughout evolution, possibly as a tradeoff for viral sensing and induction of type I IFN responses. Restoration of huTRIM5 $\alpha$-mediated restriction in DCs by blocking host pathways such as CypA binding and SUMOylation provides insight into novel therapeutic possibilities.

\subsection{Macrophages}

Macrophages are myeloid lineage cells that are resident in subepithelial tissues throughout the body. They can originate from self-renewing tissue-resident macrophages or infiltrating blood-derived monocytes [170,171]. As antigen-presenting cells, macrophages are important for bridging innate and adaptive immunity by phagocytosing extracellular pathogens, and presenting pathogen-derived antigens to $\mathrm{CD}^{+} \mathrm{T}$ cells [172]. As macrophages express the HIV-1 entry receptor CD4 and co-receptors CCR5 and CXCR4, they are themselves susceptible to HIV-1 infection [13]. In addition, HIV-1 infected macrophages can transmit virus to $\mathrm{CD} 4^{+} \mathrm{T}$ cells via a viral synapse, i.e., cell-to-cell contact, in a manner similar to that of DCs (Figure 2D) [173-175].

In macrophages, HIV-1 hijacks the early non-degradative stages of autophagy. Research using primary human macrophages, as well as THP-1 and U937 monocyte-derived macrophages, has demonstrated that the induction of autophagy with rapamycin increased extracellular HIV-1 yields [176]. In addition, inhibition of autophagy via treatment with 3MA or knock-out of Beclin1 and ATG7 resulted in a reduction in the extracellular release of infectious virus as compared to untreated cells, indicating that autophagy promotes HIV-1 maturation or release in macrophages [176]. This is in contrast with other immune cell types, as induction of autophagy in LCs, DCs, and CD4 $4^{+} \mathrm{T}$ cells results in a decrease in production of mature virions $[64,164,177]$.

In macrophages, the interaction of toll-like receptor 8 (TLR8) and HIV-1 induces autophagy by Beclin 1-dependent dephosphorylation of transcription factor EB (TFEB) and subsequently its nuclear translocation during the initial stages of HIV-1 infection $[178,179]$. Upon the induction of autophagy, HIV-1 Gag proteins co-localize with autophagy-related protein LC3 and subsequently promote Gag processing [176].

The HIV-1 Nef protein plays an important role in manipulation of host autophagy, and thereby immune evasion, in macrophages. Several studies have indicated that, by inhibiting Beclin 1 association with class III PI 3-kinase (PI3KC3) complex II, which plays a key role in autophagosome-lysosome fusion, HIV-1 Nef blocks autophagosome maturation [176,180]. Interestingly, recent studies have also indicated that Nef additionally blocks autophagy at its early initiation stages $[176,178,180,181]$.

In addition to evading host antiviral mechanisms in macrophages, HIV-1 also exploits host proteins to evade restriction. Recent studies have demonstrated that multimeric binding of host CypA proteins to the viral capsid prevents interaction of huTRIM5 $\alpha$ with the viral core, thereby blocking huTRIM $5 \alpha$-mediated restriction $[165,182]$. Correspondingly, HIV-1 viruses bearing capsid mutation P90A, which prevents CypA from interacting with the capsid, were restricted by huTRIM $5 \alpha$ in macrophages, as was also demonstrated in DCs [66,165-167]. Likewise, a construct generated by fusion of CypA to huTRIM5 $\alpha$ (hT5Cyp), inspired by the New World monkey TRIMCyp as described in Section 2.2, was able to block HIV-1 infection in human primary macrophages [19].

\section{3. $T$ Cells}

$\mathrm{CD}^{+} \mathrm{T}$ cells are key HIV- 1 target cells that can be infected directly within the mucosal environment, or following transmission from DCs (Figure 2E) [144]. In addition, HIV-1 can latently persist in long-lived CD4 ${ }^{+} \mathrm{T}$ cells in PLWH $[6,148,183]$. As in DCs, HIV-1 infection inhibits autophagy in human $\mathrm{CD}^{+} \mathrm{T}$ cells, via HIV-1 Vif interactions with LC3, and a HIV-1 Nef-dependent block in autophagy flux resulting in accumulation of endosomes and lysosomes [184,185]. Moreover, as in macrophages, multimeric binding of host CypA to 
the incoming viral capsid blocks the interaction of huTRIM $5 \alpha$ with the viral core, thereby preventing huTRIM $5 \alpha$-mediated restriction during $\mathrm{CD} 4^{+} \mathrm{T}$ cell infection. In addition, it was demonstrated recently that endogenous huTRIM $5 \alpha$ in primary human $\mathrm{CD} 4^{+} \mathrm{T}$ cells is able to bind the HIV-1 capsid post-fusion, in the absence of CypA, and thereby restrict HIV-1 [66]. In addition, HIV-1 viruses bearing capsid mutations such as P90A and G89V, which prevent CypA interacting with the capsid, were unable to infect primary human $\mathrm{CD}^{+} \mathrm{T}$ cells $[66,166,167]$. Similar to in submucosal DCs and macrophages, infection by HIV-1-P90A was restored upon depletion of huTRIM $5 \alpha$ in primary human $\mathrm{CD} 4^{+} \mathrm{T}$ cells or in Jurkat cells $[66,165]$. However, it is still unclear whether autophagy machinery plays a role in the huTRIM $5 \alpha$-mediated HIV-1 restriction in $\mathrm{CD} 4^{+} \mathrm{T}$ cells.

An additional IFN $\alpha$-dependent mechanism for huTRIM $5 \alpha$-directed control of HIV-1 infection in human cell lines and primary human $\mathrm{CD}^{+} \mathrm{T}$ cells was recently demonstrated [65]. In primary human $\mathrm{CD} 4^{+} \mathrm{T}$ cells and in U87-MG.CD4 ${ }^{+} \mathrm{CXCR} 4^{+}$cells transduced to ectopically express huTRIM $5 \alpha$, HIV-1 infection was efficiently inhibited in the presence of IFN $\alpha$, in a manner dependent on SPRY domain-mediated recognition of the viral capsid [65]. The presence of IFN $\alpha$ stimulated activation of the immunoproteasome, a proteasome isoform primarily present in immune cells, and selectively promoted ubiquitination of huTRIM5 $\alpha$, thereby accelerating its proteolytic turnover, indicating that, in the presence of IFN $\alpha$, the immunoproteasome may facilitate degradation of huTRIM $5 \alpha$-HIV-1 capsid complexes [65].

Prior to these findings, huTRIM5 $\alpha$ had long been considered to be a poor HIV-1 restrictor in a variety of cell lines. We have shown for the first time that huTRIM5 $\alpha$ is a potent restriction factor in human LCs, and that this restriction is dependent on autophagy mechanisms and cell-surface receptor usage by HIV-1. These recent studies further underline the capacity of huTRIM $5 \alpha$ to potentially restrict HIV-1 in other relevant human target cells such as DCs, $\mathrm{CD}^{+} \mathrm{T}$ cells, and macrophages. Thus, efficient huTRIM $5 \alpha$ restriction likely depends on TRIM5 $\alpha$ subcellular localization (e.g., nucleus versus cytosol) within specific cell or tissue types, but also on the ability to induce autophagy- and immunoproteasomefacilitated degradation pathways, the presence of additional cellular factors that facilitate the action of huTRIM5 $\alpha$ (e.g., Langerin), and the absence or inhibition of cellular factors that block huTRIM5 $\alpha$ recognition of the viral capsid (e.g., CypA) $[62,64,65,186]$.

\subsection{Cell-Specific and Autophagy-Dependent Restriction of HIV-1 by Additional Restriction Factors}

Cell-specific restriction is not exclusive to TRIM $5 \alpha$. For example, it has been suggested that differential SAMHD1 degradation may be an underlying contributor to the reduced permissiveness to HIV- 1 in human macrophages and DCs as compared to activated CD4 $4^{+} \mathrm{T}$ cells. In support of this, pre-treatment with Vpx, a known inducer of SAMHD1 degradation during HIV-2 or SIV infection but absent in HIV-1, promoted degradation of SAMHD1 and enhanced susceptibility of macrophages and DCs to HIV-1 [35]. However, another study showed that SAMHD1 also protects resting $\mathrm{CD} 4^{+} \mathrm{T}$ cells in a similar manner to macrophages and DCs [187].

The restriction factor MARCH8 also shows cell-specific activity. MARCH8 mRNA levels have been demonstrated to be 5 to 8 times higher in primary human terminally differentiated myeloid cells versus $\mathrm{CD}^{+} \mathrm{T}$ cells and monocytes [25]. These expression levels aligned with decreased infection in differentiated myeloid cells versus high infection in $\mathrm{CD}^{+} \mathrm{T}$ cells. Taken together, these recent data suggest that in primary cells, HIV1 restriction by different host antiviral factors is likely cell-specific, and modulated by the presence or absence, and expression or degradation levels of the restriction factors in question.

In recent years, several reports have also indicated that autophagy is involved in the activity of multiple HIV- 1 restriction factors in addition to huTRIM $5 \alpha$. For example, tetherin has been shown to interact with autophagy via multiple different pathways. In the context of HIV-1 infection, HIV-1 Vpu has been reported to downregulate tetherin expression on the cell surface by promoting its ubiquitination and subsequent intracellular 
sequestration and/or degradation within autophagosomes or lysosomes, thus potentially hijacking the autophagy pathway for the benefit of the virus $[188,189]$. Strikingly, breast cancer-associated gene 2 (BCA2, also known as Rabring7, ZNF364, or RNF115), a RINGtype E3 ubiquitin ligase, was shown to interact with tetherin to promote HIV-1 packaging into $\mathrm{CD}^{+} 3^{+}$endosomes, with the end result being lysosomal degradation of HIV-1 virions and tetherin in a manner reminiscent of tetherin-dependent autophagic degradation of damaged mitochondria in uninfected cells $[190,191]$.

On the other hand, tetherin has been demonstrated to recruit a second restriction factor, MARCH8, in order to prevent type I IFN signaling in an autophagy-dependent manner [192]. MARCH8 was recently identified as a novel antiretroviral restriction factor in terminally differentiated myeloid cells, such as macrophages and DCs, and is recruited by tetherin to ubiquitinate the RLR MAVS, leading to NDP52-dependent autophagic degradation of MAVS and, as a result, inhibition of MAVS-dependent type I IFN signaling [25,192]. The restrictive action of MARCH8 may also be autophagy-dependent, as MARCH-8directed degradation of VSV-G is not affected by treatment with a proteasome inhibitor, but was blocked upon treatment with lysosomal protease inhibitors [25]. Next to MARCH8, the closely related $\mathrm{MARCH} 2$ protein has a similar mechanism of virus restriction and potential role for autophagy [43]. It would therefore be interesting to investigate if pharmacological autophagy enhancement could promote MARCH8-or MARCH2-mediated HIV-1 restriction.

\section{TRIM5 as An Innate Immune Sensor}

By definition, restriction factors must recognize pathogen-associated molecular patterns (PAMPs) to exert their functions and interfere with the replication cycles of viruses. Recent literature highlights that restriction factors can utilize this function not only to prevent viral replication, but also to act as sensors to initiate innate immune signaling pathways to prevent infection [45-49].

The restriction factor huTRIM $5 \alpha$ is upregulated by IFN $\alpha$ signaling, as demonstrated by an increase in TRIM $5 \alpha$ mRNA expression levels upon IFN treatment, thereby intensifying blocks in HIV-1 infection [63]. However, huTRIM5 $\alpha$ is now understood to act not only as a retroviral restriction factor, but also as a PRR for sensing of incoming retroviral capsids (Figure 3) [49].

When huTRIM5 $\alpha$ is overexpressed, or recognizes a retroviral capsid, its RING domain recruits E2 ubiquitin-conjugating enzymes, thereby inducing ubiquitin-dependent signaling [49]. The multimerization of huTRIM5 $\alpha$ upon binding the retroviral N-MLV capsid results in a unique trimeric RING domain arrangement that specifically promotes polymerization of K63-linked ubiquitin chains at its $\mathrm{N}$-terminus, as demonstrated in feline (CrFK) and human (TE671) cell lines [80]. This polyubiquitination of huTRIM5 $\alpha$ subsequently activates the TAK1 (also known as MAP3K7) kinase complex, and later the AP-1 and NF- $\mathrm{kB}$ signaling pathways [49]. This ultimately results in activation of the transcription factors AP-1 and NF- $\mathrm{kB}$, which promote transcription of inflammatory mediators such as CXCL9, CXCL10, CCL8, IL-6, IL-8, and COX2, as shown in primary monocyte-derived DCs and macrophages, THP-1 monocytes and macrophages, and owl monkey kidney (OMK) cells upon recognition of the N-MLV capsid [49]. In addition, OMK cells challenged with VSV-G-pseudotyped HIV-1 upregulated secretion of IL8, CCL2, CCL4, and CSCL10 [49]. Alternatively, in $293 \mathrm{~T}$ cells, huTRIM $5 \alpha$ has also been demonstrated to negatively regulate NF- $\mathrm{kB}$ activation, via huTRIM5 $\alpha$-directed degradation of TAK- 1 binding protein (TAB)-2, in a dose-dependent manner [193]. The use of proteasomal inhibitors showed that this mechanism is independent of E3 ubiquitin ligase activity, suggesting a role for an alternative degradative pathway. Altogether, this underlines huTRIM5 $\alpha$ as a key PRR and regulator of AP-1 and NF- $\mathrm{kB}$ and AP-1 and NF- $\mathrm{kB}$-responsive inflammatory mediators, in response to sensing retroviral capsids. 


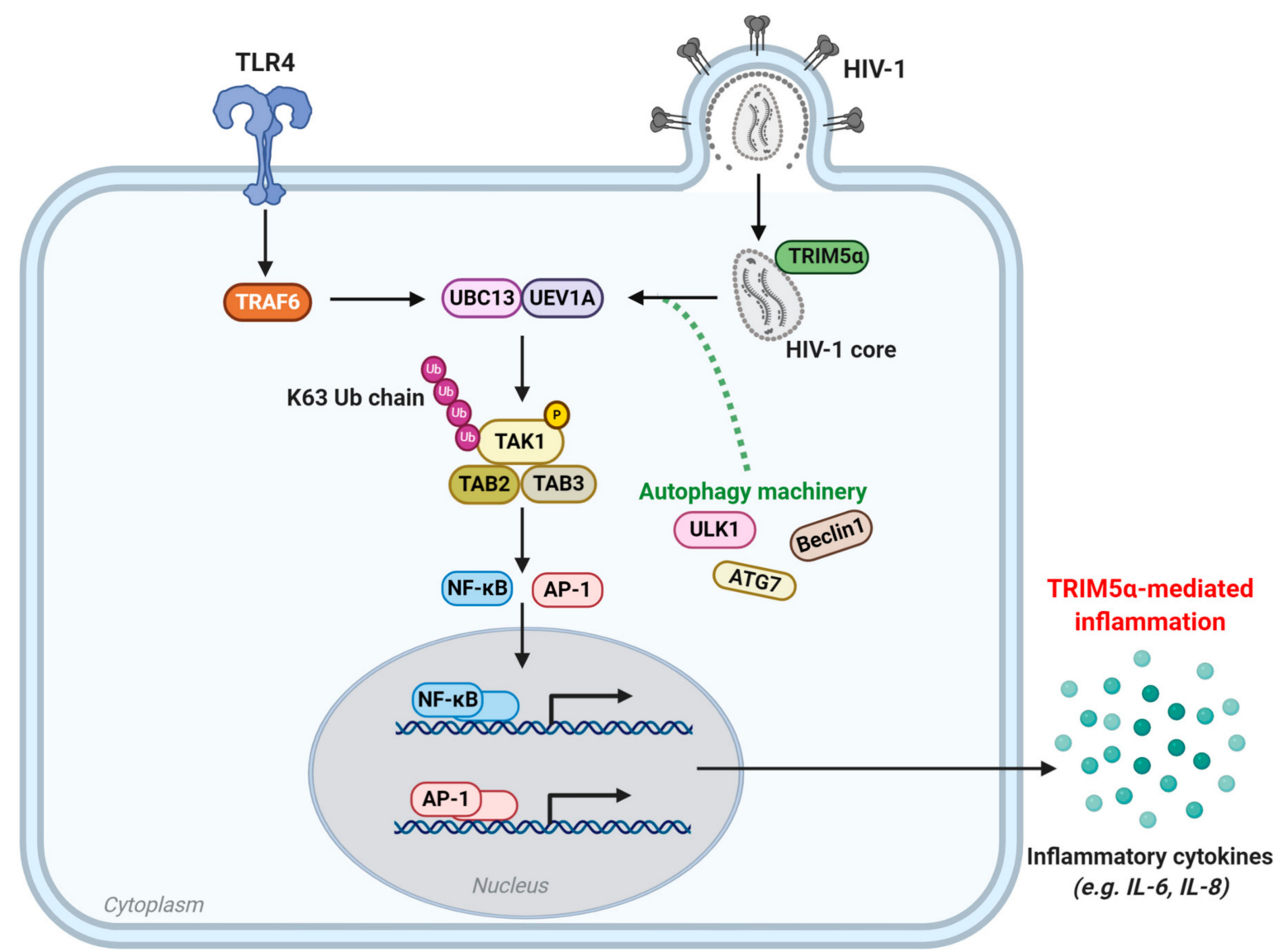

Figure 3. TRIM $5 \alpha$-mediated regulation of innate immune signaling and molecular inflammation. The TAK1 signaling pathway is activated upon TLR4 stimulation, or upon sensing of viral capsid by TRIM $5 \alpha$. Subsequently, the E3 ligase activity of TRAF6 is activated and, together with the E2 ubiquitin conjugating enzyme complex UEV1A-UBC13, promotes K63-chain linked ubiquitination and autophosphorylation of the TAK1-TAB complex. In the context of HIV-1 infection, sensing of the viral capsid by TRIM5 $\alpha$ initiates its E3 ligase activity resulting in K63-chain linked ubiquitination and autophosphorylation of the TAK1-TAB complex. Subsequently, the TAK1-TAB complex activates the transcription factors NF-kB and AP-1, leading to the transcription and ultimately secretion of pro-inflammatory cytokines such as IL-6 and IL-8. The autophagy-related proteins ULK1, Beclin1 and ATG7 are essential for TRIM5 $\alpha$ to function as an innate immune sensor. However, precisely how they contribute to the TRIM5 $\alpha$-mediated inflammation is as yet uncertain. TLR4: toll-like receptor 4, TAK1: transforming growth factor- $\beta$-activated kinase 1, TAB: TAK1-binding protein, UEV1A: ubiquitin-conjugating enzyme E2 variant 1A, UBC13: ubiquitin-conjugating enzyme E2 13, AP-1: activating protein 1, NF- $\mathrm{kB}$ : nuclear factor $\mathrm{\kappa B}$, Ub: ubiquitin, P: phosphate, IL: interleukin.

Strikingly, recent data highlight a role for autophagy in huTRIM5 $\alpha$ 's functioning as an innate sensor. Genetic depletion of key autophagy proteins such as Beclin 1, ATG7, and ULK1 was required for huTRIM5 $\alpha$-based activation of AP-1 and NF-KB, and thereby of AP-1 and NF- $\mathrm{KB}$-responsive genes [194]. In primary immune cells, induction of IFN- $\beta$ expression in response to huTRIM5 $\alpha$-restricted recognition of HIV- 1 capsid mutant (P90A) was dependent on Beclin 1, ATG7, and ULK1. Furthermore, in autophagy deficient cells, huTRIM5 $\alpha$-driven TAK1 activation, which is also Beclin 1 and ATG7-dependent, was attenuated [194]. Taken together, these data underline that autophagy contributes not only to huTRIM $5 \alpha$-mediated HIV-1 restriction, but also to the role of huTRIM5 $\alpha$ as an innate immune sensor of incoming retroviral capsids.

Notably, in primary human DCs, which are a key cell type for linking innate and adaptive immune responses, endogenous huTRIM $5 \alpha$ has been demonstrated to negatively regulate induction of type I IFN responses, as well as to positively regulate AP-1 and NF-kB-responsive inflammatory mediators, upon HIV-1 infection [49,62]. Type I IFN suppresses viral replication by upregulating IFN-stimulated genes (ISGs) that can target 
and inhibit HIV-1 at various steps of the viral life cycle [24,38,144,195]. Activation of IFN $\alpha$ upregulates transcription of ISGs including APOBEC3G, tetherin, and TRIM5 $\alpha$ itself, as well as other members of the TRIM family that participate in anti-HIV-1 immune responses such as TRIM22 $[44,196,197]$. Recent data indicate that upregulation of IFN $\alpha$ is also required for huTRIM $5 \alpha$-mediated HIV- 1 restriction in the typically HIV-1 permissive U87-MG.CD4 ${ }^{+} \mathrm{CXCR}^{+}$cell line and in primary human $\mathrm{CD} 4^{+} \mathrm{T}$ cells [65]. Altogether, these findings further underline that huTRIM $5 \alpha$ plays important intracellular roles in antiretroviral immunity and possesses the capacity for retroviral restriction; however, additional host factors or cytoplasmic counterparts are required to elicit such huTRIM $\alpha \alpha-$ mediated HIV-1 restriction.

In addition to huTRIM $5 \alpha$ sensing of exogenous retroviruses such as HIV-1, recent data suggest that the hypothesis that TRIM5 $\alpha$ evolution was driven by retroelements, or endogenous retroviruses, is well-founded $[186,198,199]$. Notably, huTRIM5 $\alpha$ was shown to both sense and restrict LINE-1 transposable elements, the only known autonomously active transposable element in humans, in HEK 293T cells [186]. Functional SPRY and B-box domains were essential for huTRIM $5 \alpha$-mediated inhibition of LINE-1 replication and insertion into the host genome. Cytoplasmic co-localization of huTRIM5 $\alpha$ and LINE-1 ribonucleoproteins (RNPs), in either cytoplasmic bodies or in a more diffuse pattern, was necessary for huTRIM $5 \alpha$-mediated LINE-1 restriction. In addition, upon sensing LINE-1 RNPs, huTRIM $5 \alpha$ activated the TAK1 kinase complex, leading to subsequent activation of the AP-1 and NF- $\kappa$ B pathways [186]. Furthermore, rhTRIMCyp also inhibited LINE-1 retrotransposition, suggesting that, as with the SPRY domain of huTRIM $5 \alpha$, CypA may also bind LINE-1 RNPs leading to retroelement restriction. Altogether, these findings indicate that the intrinsic ability of huTRIM $5 \alpha$ to restrict LINE-1 elements is reminiscent of the potency of huTRIM $5 \alpha$ to restrict exogenous retroviral capsids.

\section{In Vivo Relevancy of TRIM5 $\alpha$ and Autophagy in HIV-1 Infections}

\subsection{Impact of huTRIM5 $\alpha$ Polymorphisms on Disease Progression}

To further define the roles of huTRIM $5 \alpha$ and its relevance as a therapeutic target to treat HIV-1 infection, it is enlightening to examine the presence of single nucleotide polymorphisms (SNPs) in the huTRIM5 $\alpha$ gene, and their association with clinical outcomes and disease progression. Several epidemiological genetic studies have demonstrated a relationship between SNPs of huTRIM5 $\alpha$ and HIV-1 susceptibility, disease progression and innate and adaptive immunity, as summarized in Table 1.

With regard to HIV-1 susceptibility and disease progression, two SNPs that have been extensively studied are the arginine to glutamine mutation at gene position 136 (R136Q; TRIM5 rs10838525), and the histidine to tyrosine mutation at position 43 (H43Y; TRIM5 rs3740996). The former, TRIM5 R136Q, is located within the CC domain of huTRIM5 $\alpha$ and has been demonstrated to have a protective effect on HIV-1 susceptibility in diverse cohorts [200-202]. In concordance, in vitro studies using Cf2TH cells expressing wild-type (wt) or mutant huTRIM5 $\alpha$ and incubated with GFP-reporter HIV-1 have demonstrated that the 136Q variant of huTRIM5 $\alpha$ showed superior effects in restricting HIV-1 over wild-type 136R huTRIM5 $\alpha$ [200]. 
Table 1. Association between huTRIM5 SNPs and HIV-1 susceptibility, disease progression, and immunity.

\begin{tabular}{|c|c|c|c|c|c|c|}
\hline Effect & SNP & Domain & Implication & Outcome & $p$ & Ref. \\
\hline \multirow{6}{*}{$\begin{array}{l}\text { HIV-1 } \\
\text { susceptibility }\end{array}$} & \multirow{2}{*}{ rs3740996 } & \multirow{2}{*}{ RING } & $\begin{array}{l}\text { Higher frequencies in } \mathrm{SN}^{1} \\
\text { compared to } \mathrm{SC}^{2}\end{array}$ & Protective & $<0.043$ & {$[200,205]$} \\
\hline & & & $\begin{array}{l}\text { No association with HIV-1 } \\
\text { susceptibility }\end{array}$ & No effect & - & [203] \\
\hline & rs10838525 & $\mathrm{CC}$ & $\begin{array}{l}\text { Higher frequencies in HREU }{ }^{3} \\
\text { compared to SC }\end{array}$ & Protective & $<0.02$ & {$[200,201]$} \\
\hline & rs904375 & Intron 4 & $\begin{array}{l}\text { Higher frequencies in HIV-1 } \\
\text { positive individuals compared to } \\
\text { healthy controls }\end{array}$ & Negative & 0.46 & [208] \\
\hline & rs11038628 & Linker 2 & $\begin{array}{l}\text { Higher frequencies in HIV-1 } \\
\text { positive individuals compared to } \\
\text { healthy controls }\end{array}$ & Negative & 0.026 & [207] \\
\hline & G110R & B-box & $\begin{array}{l}\text { Higher frequencies in HIV-1 } \\
\text { positive individuals compared to } \\
\text { healthy controls }\end{array}$ & Negative & 0.002 & [204] \\
\hline \multirow{3}{*}{$\begin{array}{l}\text { Disease } \\
\text { progression }\end{array}$} & rs3740996 & RING & $\begin{array}{l}\text { Homozygous genotype resulted in } \\
\text { accelerated disease progression }\end{array}$ & Negative & - & {$[95,206]$} \\
\hline & rs10838525 & $\mathrm{CC}$ & $\begin{array}{c}\text { Protective effect observed only } \\
\text { when CXCR4-using HIV-1 variants } \\
\text { were present and when a viral load } \\
\text { of } 10^{4,5} \text { copies } / \mathrm{mL} \text { plasma was } \\
\text { used as endpoint }\end{array}$ & Partial effect & $\begin{array}{c}0.008\left(\mathrm{HZ}^{4}\right) \\
0.03\left(\mathrm{HO}^{5}\right)\end{array}$ & [206] \\
\hline & rs3824949 & 5' UTR & $\begin{array}{c}\text { Accelerated disease progression } \\
\text { when in combination with the 136Q } \\
\text { allele (rs10838525) }\end{array}$ & Negative & 0.009 & [206] \\
\hline \multirow{4}{*}{$\begin{array}{l}\text { Innate; } \\
\text { adaptive } \\
\text { immunity }\end{array}$} & rs3824949 & $5^{\prime}$ UTR & $\begin{array}{c}\text { Improved RVR }{ }^{6}, \mathrm{EVR}^{7}, \mathrm{SVR}^{8} \text { for } \\
\text { Hepatitis C virus }\end{array}$ & Protective & $<0.001$ & [211] \\
\hline & \multirow{2}{*}{$\begin{array}{l}\text { rs3824949 } \\
\text { rs7122620 }\end{array}$} & \multirow{2}{*}{$\begin{array}{l}5^{\prime} \mathrm{UTR} \\
3^{\prime} \mathrm{UTR}\end{array}$} & $\begin{array}{l}\text { Allele dose-related increase in } \\
\text { rubella antibody response }\end{array}$ & Protective & $<0.015$ & [209] \\
\hline & & & $\begin{array}{l}\text { Differences in measles specific } \\
\text { antibody levels. }\end{array}$ & Protective & $<0.02$ & [210] \\
\hline & rs7122620 & $3^{\prime}$ UTR & $\begin{array}{l}\text { Increased IL-2 secretion levels upon } \\
\text { measles vaccination }\end{array}$ & Protective & $<0.015$ & [210] \\
\hline
\end{tabular}

${ }^{1} \mathrm{SN}$ : HIV-1 seronegative individual, belonging to an HIV-1 risk group; ${ }^{2}$ SC: HIV- $1^{+}$seroconverter (weeks after HIV-1 infection during first antibodies against HIV-1 appear); ${ }^{3}$ HREU: high-risk exposed HIV-1 uninfected. ${ }^{4}$ Heterozygous for the SNP; ${ }^{5}$ homozygous for the SNP; ${ }^{6}$ RVR: rapid virologic response; ${ }^{7}$ EVR: early virologic response; ${ }^{8}$ SVR: sustained virologic response; UTR: untranslated region.

Likewise, TRIM5 H43Y, located in the RING domain, has been shown to have a protective effect on HIV-1 susceptibility, although there are discrepancies in the demonstrated efficacy of this SNP depending on the ethnicity of participants [200,203-205]. Thus, it may be that the protective effect of TRIM5 H43Y on HIV-1 susceptibility depends to some extent on interactions with other polymorphic genes that differ across genetically different populations. Contrastingly, the homozygous TRIM5 H43Y genotype was found to be predictive for an accelerated disease progression in vivo, and deleterious in vitro in CRFK cells stably transduced with H43Y huTRIM5 $\alpha[95,206]$. However, this may be explained by the fact that the RING domain is involved not only in ubiquitination of huTRIM $5 \alpha$-HIV-1 complexes but also in self-ubiquitination of huTRIM $5 \alpha$, which is important for homeostatic cycling of the host factor [127]. Thus, in uninfected individuals, mutations such as H43Y in the RING domain of huTRIM5 $\alpha$ may result in impaired self-ubiquitination and increased levels of huTRIM $5 \alpha$ in the cytoplasm, leading to increased antiretroviral activity against incoming HIV-1 virions and hence an increased protective effect against HIV-1 infection. On the other hand, the E3 ligase activity of the RING domain has also been shown to be involved in the innate immune response against HIV-1 [49]. Therefore, in infected individuals, mutations in the RING domain of huTRIM $5 \alpha$ may be associated with decreased control of HIV-1 infection by the innate immune system, thus explaining the association of SNP H43Y with accelerated disease progression. 
More recently, several SNPs in huTRIM5 $\alpha$ have been demonstrated to be more prevalent in HIV-1 infected patients as compared to healthy controls, indicating a detrimental effect of these polymorphisms on HIV-1 susceptibility. For example, expression of a G249D allele of huTRIM5 $\alpha$ SNP rs11038628 was found to be significantly higher in HIV-infected patients as compared to healthy subjects in an Indian population, and to attenuate HIV-1 restricting activity of huTRIM5 $\alpha$ in vitro [207]. The same tendency, though weaker and non-significant, was also observed in a Japanese population [207].

Similarly, a huTRIM5 $\alpha$ variant with the G110R SNP in the B-box domain, which is more frequent in Japanese HIV-1 infected patients than controls, also showed a decreased ability to control HIV-1 in vitro [204]. Interestingly, the same study also identified a truncated G176del huTRIM5 $\alpha$ variant found only in Japanese populations, which enhanced antiviral activity of co-expressed full-length huTRIM5 $\alpha$. This may be due to the G176del huTRIM5 $\alpha$ variant's enhanced functioning as an activator of innate immune responses, in line with the alternative functioning of huTRIM5 $\alpha$ as a PRR as discussed above in Section 5 [204]. Finally, a polymorphic variant of huTRIM5 $\alpha$ rs904375, located in intron 4 , has been described to affect susceptibility to HIV-1 infection, likely by impacting transcription factor-binding sites and thereby TRIM5 transcriptional activity [208].

To our knowledge, no studies specifically aiming to determine a correlation between huTRIM $5 \alpha$ SNPs and the anti-HIV-1 adaptive immune responses in PLWH have thus far been conducted. However, it has been demonstrated that the synonymous SNPs, TRIM5 rs3824949 and TRIM5 rs7122620, correlated with increased levels of rubella- and measlesspecific antibodies in humans upon vaccination against these pathogens $[209,210]$. Notably, patients possessing TRIM5 rs3824949 who were treated for chronic hepatitis C virus (HCV) were also more likely to reach rapid virologic response (RVR), early virologic response (EVR) and sustained virologic response (SVR) as compared to wt control patients [211]. The beneficial effect of TRIM5 rs3824949 in achieving SVR to HCV was also observed in HIV / HCV co-infected patients [212]. Moreover, the presence of SNPs TRIM5 rs7122620 and TRIM5 rs11820502 correlated, respectively, with increased IL-2 and IL-6 secretion upon measles vaccination [210].

These data illustrate the associations of human TRIM5 SNPs to differing HIV-1 susceptibility and disease progression underline the in vivo relevancy of huTRIM $5 \alpha$. Further underlining the importance of huTRIM5 $\alpha$ in vivo, higher expression levels of huTRIM $5 \alpha$, as well as TRIM22 and TRIM28, was demonstrated in PLWH who initiated cART treatment early, versus in those who initiated ART treatment during chronic infection phase [213]. However, no relationship between latent HIV-1 reservoir size and huTRIM $5 \alpha$ expression in cART-treated patients was demonstrated, although a second study demonstrated increased expression of huTRIM $5 \alpha$, as well as other restriction factors, over time in HIV-1 infected, untreated patients $[213,214]$.

Taken together, these results illustrate that polymorphisms and differential expression of the huTRIM $5 \alpha$ gene may impact HIV-1 susceptibility and influence HIV-1 disease progression. Expression of the huTRIM5 $\alpha$ gene and its polymorphisms can serve as a predictive biomarker to determine susceptibility to HIV-1 by HIV-1 negative individuals, as well as function as a prognostic biomarker to predict disease progression in PLWH. This utilization of TRIM5 as a biomarker may assist in the design of optimal treatment regimens and prevention of HIV-1 in the future.

\subsection{TRIM5 $\alpha$-Based Therapeutic Strategies for HIV-1}

In accordance with the long-accepted hypothesis that only rhTRIM $5 \alpha$ is able to restrict HIV-1, attempts have been made to genetically engineer $\operatorname{rhTRIM} 5 \alpha$-expressing human cells. In terms of HIV-1 therapies, the high potential of TRIM-based gene therapy strategies has been extensively reviewed [17]. One potential strategy has been to develop human mimics of TRIMCyp fusion proteins, which restrict HIV-1 when expressed in cell lines or in primary T cells and macrophages [19,85]. Interestingly, a fusion protein of TRIM21 and CypA, TRIM21Cyp, was also effective in preventing HIV-1 reverse transcription in 
human cell lines and human primary peripheral blood mononuclear cells (PBMCs) [85]. TRIM21Cyp restriction was only partially inhibited by treatment with the protease inhibitor MG132, which may be explained by TRIM21 also being a recruiter of key autophagy machinery upon binding its target proteins, including ULK1, Beclin1, ATG16L1, and GABARAP [85,215]. This could result in autophagic degradation of TRIM21Cyp-HIV-1 complexes. Fusions of CypA with TRIM1, TRIM18, and TRIM19 were also able to restrict HIV-1, with TRIM1Cyp being particularly potent, perhaps because TRIM1 is also an autophagy regulator $[129,216]$.

The potential of mutant huTRIM $5 \alpha$ proteins and chimeric rh/huTRIM $5 \alpha$ proteins has also been explored. Transduction of $\mathrm{CD}^{+} 4^{+}$human hematopoietic stem cells (HSCs) with a chimeric rh/huTRIM $5 \alpha$, in combination with a CCR5 short hairpin RNA (shRNA) and a TAR decoy, was shown to be effective in protecting against HIV-1 challenge and providing a selective survival advantage in human $\mathrm{CD} 4^{+} \mathrm{T}$ cells upon infection in a humanized mouse model [217]. A rh/huTRIM5 $\alpha$ chimeric variant was also demonstrated to efficiently restrict HIV-1 in HSC-derived macrophages in vitro and T-cells in vivo in a humanized mouse model transplanted with human fetal tissue [218]. Besides chimeric variants, single amino acid changes at positions 332 and 335 of the huTRIM5 $\alpha$ SPRY domain to more closely mimic the rhTRIM $5 \alpha$ v1 sequence were also shown to prevent the spread of HIV-1 infection by 20- to 50-fold in TE671 fibroblasts and in the human T-cell line SUP-T1 [97].

However, gene therapy with such variants of TRIM $5 \alpha$ has significant downsides. For one, it is possible that huTRIM $5 \alpha$ mutants or human mimics of TRIMCyp fusion proteins could disrupt endogenous huTRIM5 $\alpha$ function, for example, in innate immune signaling [85]. Furthermore, delivery of these treatment options would entail either transduction and re-infusion of differentiated autologous cells, which would require life-long therapy, or stem-cell based approaches that would necessitate invasive and relatively high-risk preparative ablative chemotherapy $[17,219]$. Alternatively, targeting TRIM5 $\alpha$-directed cellular mechanisms such as proteasomal activity, autophagy-mediated degradation, and antiviral inflammatory signaling may represent innovative and relevant approaches to capitalize on TRIM5 $\alpha$-mediated antiviral functions.

\subsection{Impact of Autophagy on HIV-1 Disease Progression and Comorbidities}

As outlined above in Section 4, HIV-1 has been demonstrated to evade autophagy in several different cell types in vitro, including DCs, macrophages, and $\mathrm{CD} 4^{+} \mathrm{T}$ cells via viral molecules such as Vif and Nef $[64,153,184,185]$. In vivo and ex vivo studies have further underlined the importance of autophagy in anti-HIV-1 immunity. Ex vivo studies using PBMCs derived from PLWH have shown that long-term non-progressor PLWH contain more specialized autophagy vesicles than those from normal progressors [220]. Notably, viral production and viral load in ex vivo PBMCs derived from PLWH were reduced upon treatment with the autophagy-enhancing drug rapamycin [220]. In line with this finding, enhancement of autophagy in monocyte-derived DCs and macrophages and $\mathrm{CD} 4^{+} \mathrm{T}$ cells in vitro has shown similar successes in controlling HIV-1 infection or promoting autophagydependent apoptosis of HIV-1 infected cells [164,221,222]. Successful control of HIV-1 infection is likely dependent on the level of induced autophagy. Productive HIV-1 infection has been detected in $\mathrm{T}$ cell lines and primary human monocyte-derived macrophages with moderate amounts of autophagosomes present, whereas strong autophagy induction inhibits viral replication and infection [223]. This indicates that intrinsic autophagy mechanisms, and, more importantly, pharmaceutical enhancement of autophagy, can control HIV-1 infection.

Furthermore, autophagy dysfunction has been associated with increased risk for HIV1 associated comorbidities in cART-treated HIV-1 patients and animal models [224,225]. Cardiovascular disease is a leading comorbidity for PLWH, even in those who are cARTtreated [226]. The HIV-1 Nef protein, which is thought to be released extracellularly by HIV-1 infected CD4 ${ }^{+} \mathrm{T}$ cells and is detectable in the serum of HIV-1-positive patients, accumulates in cardiomyocytes where it dysregulates autophagy leading to cardiomyocyte 
cytotoxicity and death. Strikingly, this effect could be reversed in vitro by treatment with the autophagy-inducing drug rapamycin [225]. Nef is not the only HIV-1 protein affecting cardiomyocytes; the HIV-1 protein Tat also has a profound impact on these cells. Recent research has shown that transduction of cardiomyocytes with adenoviral-Tat impaired mitochondrial $\mathrm{Ca}^{+}$uptake and the electrophysiological activity of the cardiomyocytes. In addition, Tat impaired the protein clearance function of autophagy under hypoxic conditions, due to a reduction in ubiquitination and dysregulation of autophagy proteins p62 and LC3-11 [227]. As well as Nef and Tat, the HIV-1 proteins Env, Gag, Vif, and p24 have all been shown to impact autophagy pathways or serve as specific substrates for autophagy, depending on the cell type, and thereby evade and dysregulate the autophagy machinery as reviewed in [228].

The central nervous system is also an important target of HIV-1, and neurological impairment ranging from severe HIV-1 associated dementia in untreated PLWH to minor cognitive disorders in cART-treated PLWH have been described $[229,230]$. In post-mortem brains from HIV-1 patients with encephalitis, levels of autophagy proteins such as Beclin 1, ATG5, ATG7, and LC3-II were significantly increased, as compared to the brains from HIV-1 positive patients without HIV-1 encephalitis or uninfected controls [224]. In line with this finding, in vitro studies showed that adding the supernatant from HIV-1 infected primary macrophages to human fetal neurons resulted in the increase in autophagy-proteins Beclin1 and ATG5, but no LC3-1l formation was detected [231]. This suggests that while the early steps of autophagy were promoted in neurons, HIV-1 inhibits the later degradative steps of autophagy leading to protein accumulation and thereby neuronal toxicity. Strikingly, the same study showed that autophagy-inducing rapamycin treatment of neurons resulted in protection against HIV-1 toxicity [231]. Taken together, these data are illustrative of widespread autophagy dysregulation during HIV-1 disease progression. Nevertheless, the in vivo relevancy of autophagy in non-progressor PLWH and the beneficial effects of autophagy inducers in vitro showcase the protective role of autophagy mechanisms in HIV-1 disease progression and comorbidity development, and the therapeutic potential to harness autophagy for HIV-1 management.

\subsection{Harnessing Autophagy for HIV-1 Management}

As demonstrated by several in vitro and ex vivo studies, boosting autophagy in HIV-1 target cells may be an economically feasible and therapeutically effective way to treat HIV-1 infection. Indeed, autophagy-targeting drugs have already proved effective in intervening in HIV-1 infection in human macrophages, DCs, PBMCs, and CD4 ${ }^{+}$ T cells $[164,220-222,232]$. For example, TLR8-induced autophagy inhibits HIV-1 release by infected human monocyte-derived macrophages via a vitamin-D dependent mechanism, and treatment of human monocyte-derived macrophages with vitamin D promoted autophagy-mediated inhibition of HIV-1 replication [221,233]. Treatment with the autophagy-enhancing peptide Tat-vFLIP- $\alpha 2$ could also initiate autophagy-dependent cell death in HIV-1 infected human macrophages [232]. Similarly, treatment with a Tat-Beclin 1 peptide also induced autophagy and had a protective effect against HIV-1 infection of human monocyte-derived macrophages [234]. Comparable effects have been demonstrated in ex vivo PBMCs and $\mathrm{CD} 4^{+} \mathrm{T}$ cells derived from HIV-infected individuals, where treatment with the autophagy enhancing drug rapamycin or DIABLO/SMAC mimetics, respectively, reduced HIV-1 replication, or selectively induced killing of latently infected $\mathrm{CD} 4^{+} \mathrm{T}$ cells [220,222]. Likewise, rapamycin treatment could also reverse the HIV-1 Nef-induced block in autophagosome maturation in cardiomyocytes [225].

Strikingly, we have recently demonstrated that treatment with autophagy-enhancing drugs limits HIV-1 acquisition and suppresses ongoing HIV-1 replication in ex vivo human tissue-derived $\mathrm{CD} 11 \mathrm{c}^{+} \mathrm{DCs}$ and $\mathrm{CD} 4^{+} \mathrm{T}$ cells [164]. These data were also corroborated in vaginal and intestinal tissues. Prophylactic treatment with autophagy-enhancing drugs carbamazepine or everolimus significantly reduced HIV-1 acquisition by subepithelial $\mathrm{CD}_{11 \mathrm{c}^{+}} \mathrm{DC}$ s and $\mathrm{CD}^{+} \mathrm{T}$ cells. Notably, a cell-specific effect of post-infection treatment 
with autophagy drugs was observed. Treatment with carbamazepine, everolimus, or rapamycin reduced HIV-1 replication in infected ex vivo $\mathrm{CD}^{+}{ }^{+} \mathrm{T}$ cells, while only therapeutic rapamycin administration intervened in ongoing HIV-1 infection in CD $11 \mathrm{c}^{+}$DCs. Taken together, these data support harnessing autophagy as a relevant emerging target for HIV-1 therapies [164].

Such autophagy-enhancing drugs may circumvent HIV-1-mediated down-regulation of the autophagy system in distinct HIV-1 target cells without usurping alternative signaling roles of the endogenous proteins. This could permit not only more efficient huTRIM $5 \alpha-$ mediated HIV-1 restriction in immune cells such as LCs, which possess an intrinsic capacity for such restriction, but also promote huTRIM $5 \alpha$-mediated HIV-1 restriction in permissive immune cells such as DCs and CD4 ${ }^{+}$T cells, in which HIV-1 likely circumvents huTRIM5 $\alpha$ mediated restriction by blocking autophagy. Finally, autophagic degradation of non-self peptides is well-established to promote antigen presentation $[235,236]$. Thus, degradation of HIV-1 via autophagy could potentially promote presentation of HIV-1 specific antigens by DCs, enhancing the HIV-1 specific T-cell adaptive immune response. In summary, the use of autophagy enhancers in combination with current cART therapies may have the potential to both reboot the restrictive capacities of host restriction factors for HIV-1 in primary human immune cells and maximize the antiviral immune response mediated by huTRIM5 $\alpha$, as well as other autophagy-interacting restriction factors.

\section{Conclusions and Outlook}

To reiterate previous reviews, a silver-bullet strategy for HIV-1 cure is unlikely to work, given the hypervariability of the retrovirus and its many adaptations to evade host immune responses and establish viral reservoirs [17,237]. Rather, we should hedge our bets on exploiting a panel of strategies to eradicate HIV-1, including leveraging natural restriction factors, such as TRIM $5 \alpha$, and harnessing the power of protective host pathways, such as autophagy and the immunoproteasome, to prevent infection and promote innate immune responses. Here, we have provided an overview of the multifaceted functions of TRIM5 $\alpha$, which span from virus sensing and restriction to induction of innate immune responses. We have also outlined the impact of TRIM5 $\alpha$ genetic polymorphisms on HIV-1 susceptibility and HIV-1 disease progression and comorbidities of PLWH. We propose a novel conceptualization of TRIM $5 \alpha$-mediated HIV-1 restriction. Until recently, TRIM5 $\alpha$ mediated HIV-1 restriction has primarily been considered to be limited to the rhesus orthologue, which relies on early disintegration of the HIV-1 capsid and subsequently proteasomal degradation to exert its protective function. The demonstrated functionalities of huTRIM5 $\alpha$ to prevent LINE-1 retrotransposition, restrict HIV-1 in primary human LCs and in DCs treated with SUMOylation inhibitor, and mediate immunoproteasomedependent restriction of HIV-1 in $\mathrm{CD}^{+}{ }^{+} \mathrm{T}$ cells underpin the intrinsic ability of the human huTRIM5 $\alpha$ orthologue to restrict HIV-1 infection $[62,64,65,186]$.

Based on this recent literature, we propose that TRIM $5 \alpha$ should be conceptualized as a cell-specific restriction factor with a varied portfolio of protective functions, including functionality as an autophagic effector, innate immune retroviral sensor, promoter of viral degradation, and potentially a linker of innate antiviral and adaptive immunity. We have also expanded on the roles of autophagy in the context of HIV-1, and propose that pharmacological modulation of autophagy mechanisms may be a financially and therapeutically efficacious treatment option in combination with current ART.

Author Contributions: Conceptualization, A.P.M.C. and C.M.S.R.; writing-original draft preparation, A.P.M.C., B.C., and C.M.S.R.; writing-review and editing, A.G.R., A.P.M.C., and C.M.S.R.; supervision, C.M.S.R. All authors have read and agreed to the published version of the manuscript.

Funding: This work was funded by an AMC PhD Scholarship (A.P.M.C.), AMC PhD grant (A.G.R.) and Dutch Research Council (NWO-ZonMw) VIDI grant 91718331 (C.M.S.R.).

Institutional Review Board Statement: Not applicable.

Informed Consent Statement: Not applicable. 
Data Availability Statement: No new data were created or analyzed in this study. Data sharing is not applicable to this article.

Acknowledgments: We would like to acknowledge BioRender.com, for providing the software in which figures were constructed. We would also like to acknowledge the valuable input from and discussions with members of the Autophagy-directed Immunity, Host Defense, and Laboratory for Viral Immune Pathogenesis groups from the Department of Experimental Immunology.

Conflicts of Interest: The authors declare no conflict of interest.

\section{References}

1. World Health Organization. HIV/AIDS Factsheets. Available online: https://www.who.int/news-room/fact-sheets/detail/hivaids (accessed on 19 October 2020).

2. HIV CAUSAL Collaboration; Ray, M.; Logan, R.; Sterne, J.A.C.; Hernández-Díaz, S.; Robins, J.M.; Sabin, C.; Bansi, L.; van Sighem, A.; de Wolf, F.; et al. The effect of combined antiretroviral therapy on the overall mortality of HIV-infected individuals. AIDS 2010, 24, 123-137.

3. Jean, M.J.; Fiches, G.; Hayashi, T.; Zhu, J.; Fiches, G. Current strategies for elimination of HIV-1 latent reservoirs using chemical compounds targeting host and viral factors. AIDS Res. Hum. Retrovir. 2019, 35, 1-24. [CrossRef]

4. Hammer, S.M.; Katzenstein, D.A.; Hughes, M.D.; Gundacker, H.; Schooley, R.T.; Haubrich, R.H.; Henry, W.K.; Lederman, M.M.; Phair, J.P.; Niu, M.T.; et al. A trial comparing nucleoside monotherapy with combination therapy in HIV-infected adults with CD4 cell counts from 200 to 500 per cubic millimeter. N. Engl. J. Med. 1996, 335, 1081-1090. [CrossRef]

5. $\quad$ Egger, M.; Hirschel, B.; Francioli, P.; Sudre, P.; Wirz, M.; Flepp, M.; Rickenbach, M.; Malinverni, R.; Vernazza, P.; Battegay, M. Impact of new antiretroviral combination therapies in HIV infected patients in Switzerland: Prospective multicentre study. Swiss HIV cohort study. BMJ 1997, 315, 1194-1199. [CrossRef] [PubMed]

6. Chun, T.; Nickle, D.C.; Justement, J.S.; Meyers, J.H.; Roby, G.; Hallahan, C.W.; Kottilil, S.; Moir, S.; Mican, J.M.; Mullins, J.I.; et al. Persistence of HIV in gut-associated lymphoid tissue despite long-term antiretroviral therapy. J. Infect. Dis. 2008, 197, 714-720. [CrossRef] [PubMed]

7. Popov, S.; Chenine, A.-L.; Gruber, A.; Li, P.-L.; Ruprecht, R.M. Long-term productive human immunodeficiency virus infection of CD1a-sorted myeloid dendritic cells. J. Virol. 2005, 79, 602-608. [CrossRef]

8. Finzi, D.; Blankson, J.N.; Siliciano, J.D.; Margolick, J.B.; Chadwick, K.; Pierson, T.C.; Smith, K.; Lisziewicz, J.; Lori, F.; Flexner, C.; et al. Latent infection of CD4+ T cells provides a mechanism for lifelong persistence of HIV-1, even in patients on effective combination therapy. Nat. Med. 1999, 5, 512-517. [CrossRef]

9. Bruner, K.M.; Hosmane, N.N.; Siliciano, R.F. Towards an HIV-1 cre: Measuring the latent reservoir. Trends Microbiol. 2015, 23, 192-203. [CrossRef]

10. Mait-Kaufman, J.; Fakioglu, E.; Mesquita, P.M.; Elliott, J.; Lo, Y.; Madan, R.P. Chronic HIV infection is associated with upregulation of proinflammatory cytokine and chemokine and alpha defensin gene expression in colorectal mucosa. AIDS Res. Hum. Retrovir. 2015, 31, 615-622. [CrossRef] [PubMed]

11. Guaraldi, G.; Orlando, G.; Zona, S.; Menozzi, M.; Carli, F.; Garlassi, E.; Berti, A.; Rossi, E.; Roverato, A.; Palella, F. Premature agerelated comorbidities among HIV-infected persons compared with the general population. Clin. Infect. Dis. 2011, 53, 1120-1126. [CrossRef]

12. Klatt, N.R.; Chomont, N.; Douek, D.C.; Deeks, S.G. Immune activation and HIV persistence: Implications for curative approaches to HIV infection. Immunol. Rev. 2013, 254, 326-342. [CrossRef]

13. Kruize, Z.; Kootstra, N.A. The role of macrophages in HIV-1 persistence and pathogenesis. Front. Microbiol. 2019, 10, 2828. [CrossRef] [PubMed]

14. Notario-Pérez, F.; Ruiz-Caro, R.; Veiga-Ochoa, M.-D. Historical development of vaginal microbicides to prevent sexual transmission of HIV in women: From past failures to future hopes. Drug Des. Dev. Ther. 2017, 11, 1767-1787. [CrossRef]

15. McKinnon, L.R.; Liebenberg, L.J.; Yende-Zuma, N.; Archary, D.; Ngcapu, S.; Sivro, A.; Nagelkerke, N.; Lerma, J.G.G.; Kashuba, A.D.; Masson, L.; et al. Genital inflammation undermines the effectiveness of tenofovir gel in preventing HIV acquisition in women. Nat. Med. 2018, 24, 491-496. [CrossRef] [PubMed]

16. Klatt, N.R.; Cheu, R.; Birse, K.; Zevin, A.S.; Perner, M.; Noël-Romas, L.; Grobler, A.; Westmacott, G.; Xie, I.Y.; Butler, J.; et al. Vaginal bacteria modify HIV tenofovir microbicide efficacy in African women. Science 2017, 356, 938-945. [CrossRef] [PubMed]

17. Chan, E.; Towers, G.J.; Qasim, W. Gene therapy strategies to exploit TRIM derived restriction factors against HIV-1. Viruses 2014, 6, 243-263. [CrossRef]

18. Besnard, E.; Hakre, S.; Kampmann, M.; Lim, H.W.; Hosmane, N.N.; Martin, A.; Bassik, M.C.; Verschueren, E.; Battivelli, E.; Chan, J.; et al. The mTOR Complex Controls HIV Latency. Cell Host Microbe 2016, 20, 785-797. [CrossRef] [PubMed]

19. Neagu, M.R.; Ziegler, P.; Pertel, T.; Strambio-De-Castillia, C.; Grütter, C.; Martinetti, G.; Mazzucchelli, L.; Grütter, M.; Manz, M.G.; Luban, J. Potent inhibition of HIV-1 by TRIM5-cyclophilin fusion proteins engineered from human components. J. Clin. Investig. 2009, 119, 3035-3047. [CrossRef]

20. Kaufmann, S.H.E.; Dorhoi, A.; Hotchkiss, R.S.; Bartenschlager, R. Host-directed therapies for bacterial and viral infections. Nat. Rev. Drug Discov. 2018, 17, 35-56. [CrossRef] 
21. Colomer-Lluch, M.; Ruiz, A.; Moris, A.; Prado, J.G. Restriction factors: From intrinsic viral restriction to shaping cellular immunity against HIV-1. Front. Immunol. 2018, 9, 2876. [CrossRef]

22. Yu, J.; Li, M.; Wilkins, J.; Ding, S.; Swartz, T.H.; Esposito, A.M.; Zheng, Y.-M.; Freed, E.O.; Liang, C.; Chen, B.K.; et al. IFITM proteins restrict HIV-1 infection by antagonizing the envelope glycoprotein. Cell Rep. 2015, 13, 145-156. [CrossRef] [PubMed]

23. Perez-Caballero, D.; Zang, T.; Ebrahimi, A.; McNatt, M.W.; Gregory, D.A.; Johnson, M.C.; Bieniasz, P.D. Tetherin inhibits HIV-1 release by directly tethering virions to cells. Cell 2009, 139, 499-511. [CrossRef] [PubMed]

24. Malim, M.H.; Bieniasz, P.D. HIV restriction factors and mechanisms of evasion. Cold Spring Harb. Perspect. Med. 2012, 2, a006940. [CrossRef]

25. Tada, T.; Zhang, Y.; Koyama, T.; Tobiume, M.; Tsunetsugu-Yokota, Y.; Yamaoka, S.; Fujita, H.; Tokunaga, K. MARCH8 inhibits HIV-1 infection by reducing virion incorporation of envelope glycoproteins. Nat. Med. 2015, 21, 1502-1507. [CrossRef]

26. O'Connor, C.; Pertel, T.; Gray, S.; Robia, S.L.; Bakowska, J.C.; Luban, J.; Campbell, E.M. p62/Sequestosome-1 associates with and sustains the expression of retroviral restriction factor TRIM5 $\alpha$. J. Virol. 2010, 84, 5997-6006. [CrossRef]

27. Simon, V.; Bloch, N.; Landau, N.R. Intrinsic host restrictions to HIV-1 and mechanisms of viral escape. Nat. Immunol. 2015, 16, 546-553. [CrossRef] [PubMed]

28. Briggs, J.A.; Kräusslich, H.-G. The molecular architecture of HIV. J. Mol. Biol. 2011, 410, 491-500. [CrossRef] [PubMed]

29. Engelman, A.; Cherepanov, P. The structural biology of HIV-1: Mechanistic and therapeutic insights. Nat. Rev. Genet. 2012, 10, 279-290. [CrossRef]

30. Usami, Y.; Wu, Y.; Göttlinger, H.G. SERINC3 and SERINC5 restrict HIV-1 infectivity and are counteracted by Nef. Nature 2015, 526, 218-223. [CrossRef] [PubMed]

31. Compton, A.A.; Bruel, T.; Porrot, F.; Mallet, A.; Sachse, M.; Euvrard, M.; Liang, C.; Casartelli, N.; Schwartz, O. IFITM proteins incorporated into HIV-1 virions impair viral fusion and spread. Cell Host Microbe 2014, 16, 736-747. [CrossRef]

32. Lu, J.; Pan, Q.; Rong, L.; Liu, S.-L.; Liang, C. The IFITM proteins inhibit HIV-1 infection. J. Virol. 2011, 85, 2126-2137. [CrossRef]

33. Tartour, K.; Appourchaux, R.; Gaillard, J.; Nguyen, X.-N.; Durand, S.; Turpin, J.; Beaumont, E.; Roch, E.; Berger, G.; Mahieux, R.; et al. IFITM proteins are incorporated onto HIV-1 virion particles and negatively imprint their infectivity. Retrovirology 2014, 11, 1-14. [CrossRef] [PubMed]

34. Hultquist, J.F.; Harris, R.S. Leveraging APOBEC3 proteins to alter the HIV mutation rate and combat AIDS. Future Virol. 2009, 4, 605-619. [CrossRef]

35. Laguette, N.; Sobhian, B.; Casartelli, N.; Ringeard, M.; Chable-Bessia, C.; Ségéral, E.; Yatim, A.; Emiliani, S.; Schwartz, O.; Benkirane, M. SAMHD1 is the dendritic- and myeloid-cell-specific HIV-1 restriction factor counteracted by Vpx. Nature 2011, 474, 654-657. [CrossRef]

36. Wu, L. SAMHD1: A new contributor to HIV-1 restriction in resting CD4+T-cells. Retrovirology 2012, 9, 1-5. [CrossRef]

37. Lahouassa, H.; Daddacha, W.; Hofmann, H.; Ayinde, D.; Logue, E.C.; Dragin, L.; Bloch, N.; Maudet, C.; Bertrand, M.; Gramberg, T.; et al. SAMHD1 restricts the replication of human immunodeficiency virus type 1 by depleting the intracellular pool of deoxynucleoside triphosphates. Nat. Immunol. 2012, 13, 223-228. [CrossRef] [PubMed]

38. Goujon, C.; Malim, M.H. Characterization of the alpha interferon-induced postentry block to HIV-1 infection in primary human macrophages and T cells. J. Virol. 2010, 84, 9254-9266. [CrossRef] [PubMed]

39. Fricke, T.; White, T.E.; Schulte, B.; Vieira, D.A.D.S.A.; Dharan, A.; Campbell, E.M.; Brandariz-Nuñez, A.; Diaz-Griffero, F. MxB binds to the HIV-1 core and prevents the uncoating process of HIV-1. Retrovirology 2014, 11, 1-14. [CrossRef] [PubMed]

40. Li, M.; Kao, E.; Gao, X.; Sandig, H.; Limmer, K.; Pavon-Eternod, M.; Jones, T.E.; Landry, S.; Pan, T.; Weitzman, M.D.; et al. Codon-usage-based inhibition of HIV protein synthesis by human schlafen 11. Nature 2012, 491, 125-128. [CrossRef]

41. Hotter, D.; Sauter, D.; Kirchhoff, F. Guanylate binding protein 5: Impairing virion infectivity by targeting retroviral envelope glycoproteins. Small GTPases 2017, 8, 31-37. [CrossRef] [PubMed]

42. Krapp, C.; Hotter, D.; Gawanbacht, A.; McLaren, P.J.; Kluge, S.F.; Stürzel, C.M.; Mack, K.; Reith, E.; Engelhart, S.; Ciuffi, A.; et al. Guanylate binding protein (GBP) 5 is an interferon-inducible inhibitor of HIV-1 infectivity. Cell Host Microbe 2016, 19, 504-514. [CrossRef] [PubMed]

43. Zhang, Y.; Lu, J.; Liu, X. MARCH2 is upregulated in HIV-1 infection and inhibits HIV-1 production through envelope protein translocation or degradation. Virology 2018, 518, 293-300. [CrossRef] [PubMed]

44. Van Damme, N.; Goff, D.; Katsura, C.; Jorgenson, R.L.; Mitchell, R.S.; Johnson, M.C.; Stephens, E.B.; Guatelli, J.C. The interferoninduced protein BST-2 restricts HIV-1 release and is downregulated from the cell surface by the viral VPU protein. Cell Host Microbe 2008, 3, 245-252. [CrossRef]

45. Casartelli, N.; Guivel-Benhassine, F.; Bouziat, R.; Brandler, S.; Schwartz, O.; Moris, A. The antiviral factor APOBEC3G improves CTL recognition of cultured HIV-infected T cells. J. Exp. Med. 2010, 207, 39-49. [CrossRef] [PubMed]

46. Galão, R.P.; Le Tortorec, A.; Pickering, S.; Kueck, T.; Neil, S.J.D. Innate sensing of HIV-1 assembly by tetherin induces NFkBdependent proinflammatory responses. Cell Host Microbe 2012, 12, 633-644. [CrossRef]

47. Ayinde, D.; Bruel, T.; Cardinaud, S.; Porrot, F.; Prado, J.G.; Moris, A.; Schwartz, O. SAMHD1 limits HIV-1 antigen presentation by monocyte-derived dendritic cells. J. Virol. 2015, 89, 6994-7006. [CrossRef] [PubMed]

48. Li, S.X.; Barrett, B.S.; Guo, K.; Kassiotis, G.; Hasenkrug, K.J.; Dittmer, U.; Gibbert, K.; Santiago, M.L. Tetherin/BST-2 promotes dendritic cell activation and function during acute retrovirus infection. Sci. Rep. 2016, 6, 1-12. [CrossRef] 
49. Pertel, T.; Hausmann, S.; Morger, D.; Züger, S.; Guerra, J.; Lascano, J.; Reinhard, C.; Santoni, F.A.; Uchil, P.D.; Chatel, L.; et al. TRIM5 is an innate immune sensor for the retrovirus capsid lattice. Nature 2011, 472, 361-365. [CrossRef]

50. Stremlau, M.; Owens, C.M.; Perron, M.J.; Kiessling, M.K.H.; Autissier, P.; Sodroski, J. The cytoplasmic body component TRIM5 $\alpha$ restricts HIV-1 infection in Old World monkeys. Nature 2004, 427, 848-853. [CrossRef] [PubMed]

51. Hofmann, W.; Schubert, D.; LaBonte, J.; Munson, L.; Gibson, S.; Scammell, J.; Ferrigno, P.; Sodroski, J. Species-Specific, Postentry Barriers to Primate Immunodeficiency Virus Infection. J. Virol. 1999, 73, 10020-10028. [CrossRef] [PubMed]

52. Himathongkham, S.; Luciw, P.A. Restriction of HIV-1 (subtype B) replication at the entry step in rhesus macaque cells. Virology 1996, 219, 485-488. [CrossRef]

53. Shibata, R.; Sakai, H.; Kawamura, M.; Tokunaga, K.; Adachi, A. Early replication block of human immunodeficiency virus type 1 in monkey cells. J. Gen. Virol. 1995, 76, 2723-2730. [CrossRef] [PubMed]

54. Owens, C.M.; Yang, P.C.; Göttlinger, H.; Sodroski, J. Human and simian immunodeficiency virus capsid proteins are major viral determinants of early, postentry replication blocks in simian cells. J. Virol. 2003, 77, 726-731. [CrossRef]

55. Münk, C.; Brandt, S.M.; Lucero, G.; Landau, N.R. A dominant block to HIV-1 replication at reverse transcription in simian cells. Proc. Natl. Acad. Sci. USA 2002, 99, 13843-13848. [CrossRef] [PubMed]

56. Anderson, J.L.; Campbell, E.M.; Wu, X.; Vandegraaff, N.; Engelman, A.; Hope, T.J. Proteasome inhibition reveals that a functional preintegration complex intermediate can be generated during restriction by diverse TRIM5 proteins. J. Virol. 2006, 80, 9754-9760. [CrossRef]

57. Danielson, C.M.; Cianci, G.C.; Hope, T.J. Recruitment and dynamics of proteasome association with rhTRIM $5 \alpha$ cytoplasmic complexes during HIV-1 infection. Traffic 2012, 13, 1206-1217. [CrossRef] [PubMed]

58. Diaz-Griffero, F.; Qin, X.-R.; Hayashi, F.; Kigawa, T.; Finzi, A.; Sarnak, Z.; Lienlaf, M.; Yokoyama, S.; Sodroski, J. A B-box 2 surface patch important for TRIM5 $\alpha$ self-association, capsid binding avidity, and retrovirus restriction. J. Virol. 2009, 83, 10737-10751. [CrossRef] [PubMed]

59. Li, X.; Sodroski, J. The TRIM5 $\alpha$ B-box 2 domain promotes cooperative binding to the retroviral capsid by mediating higher-order self-association. J. Virol. 2008, 82, 11495-11502. [CrossRef]

60. Li, Y.-L.; Chandrasekaran, V.; Carter, S.D.; Woodward, C.L.; Christensen, D.E.; Dryden, K.A.; Pornillos, O.; Yeager, M.; GanserPornillos, B.K.; Jensen, G.J.; et al. Primate TRIM5 proteins form hexagonal nets on HIV-1 capsids. eLife 2016, 5, e16269. [CrossRef]

61. Carthagena, L.; Parise, M.C.; Ringeard, M.; Chelbi-Alix, M.K.; Hazan, U.; Nisole, S. Implication of TRIM alpha and TRIMCyp in interferon-induced anti-retroviral restriction activities. Retrovirology 2008, 5, 59. [CrossRef]

62. Portilho, D.M.; Fernandez, J.; Ringeard, M.; Machado, A.K.; Boulay, A.; Mayer, M.; Mullertrutwin, M.C.; Beignon, A.-S.; Kirchhoff, F.; Nisole, S.; et al. Endogenous TRIM $5 \alpha$ function is regulated by SUMOylation and nuclear sequestration for efficient innate sensing in dendritic cells. Cell Rep. 2016, 14, 355-369. [CrossRef]

63. Asaoka, K.; Ikeda, K.; Hishinuma, T.; Horie-Inoue, K.; Takeda, S.; Inoue, S. A retrovirus restriction factor TRIM5 $\alpha$ is transcriptionally regulated by interferons. Biochem. Biophys. Res. Commun. 2005, 338, 1950-1956. [CrossRef]

64. Ribeiro, C.M.S.; Sarrami-Forooshani, R.; Setiawan, L.C.; Zijlstra-Willems, E.M.; Van Hamme, J.L.; Tigchelaar, W.; Van Der Wel, N.N.; Kootstra, N.A.; Gringhuis, S.I.; Geijtenbeek, T.B.H. Receptor usage dictates HIV-1 restriction by human TRIM5 $\alpha$ in dendritic cell subsets. Nature 2016, 540, 448-452. [CrossRef]

65. Jimenez-Guardeño, J.M.; Apolonia, L.; Betancor, G.; Malim, M.H. Immunoproteasome activation enables human TRIM5 $\alpha$ restriction of HIV-1. Nat. Microbiol. 2019, 4, 933-940. [CrossRef]

66. Selyutina, A.; Persaud, M.; Simons, L.M.; Bulnes-Ramos, A.; Buffone, C.; Martinez-Lopez, A.; Scoca, V.; Di Nunzio, F.; Hiatt, J.; Marson, A.; et al. Cyclophilin A prevents HIV-1 restriction in lymphocytes by blocking human TRIM5 $\alpha$ binding to the viral core. Cell Rep. 2020, 30, 3766-3777.e6. [CrossRef]

67. Nisole, S.; Stoye, J.P.; Saï, A. TRIM family proteins: Retroviral restriction and antiviral defence. Nat. Rev. Genet. 2005, 3, 799-808. [CrossRef] [PubMed]

68. Stremlau, M.; Perron, M.; Welikala, S.; Sodroski, J. Species-specific variation in the B30.2(SPRY) domain of TRIM5 $\alpha$ determines the potency of human immunodeficiency virus restriction. J. Virol. 2005, 79, 3139-3145. [CrossRef]

69. Perez-Caballero, D.; Hatziioannou, T.; Yang, A.; Cowan, S.; Bieniasz, P.D. Human tripartite motif $5 \alpha$ domains responsible for retrovirus restriction activity and specificity. J. Virol. 2005, 79, 8969-8978. [CrossRef] [PubMed]

70. Diaz-Griffero, F.; Kar, A.; Perron, M.; Xiang, S.-H.; Javanbakht, H.; Li, X.; Sodroski, J. Modulation of retroviral restriction and proteasome inhibitor-resistant turnover by changes in the TRIM5 $\alpha$ B-Box 2 domain. J. Virol. 2007, 81, 10362-10378. [CrossRef] [PubMed]

71. Roganowicz, M.D.; Komurlu, S.; Mukherjee, S.; Plewka, J.; Alam, S.L.; Skorupka, K.A.; Wan, Y.; Dawidowski, D.; Cafiso, D.S.; Ganser-Pornillos, B.K.; et al. TRIM5 $\alpha$ SPRY/coiled-coil interactions optimize avid retroviral capsid recognition. PLoS Pathog. 2017, 13, e1006686. [CrossRef]

72. Ganser-Pornillos, B.K.; Chandrasekaran, V.; Pornillos, O.; Sodroski, J.G.; Sundquist, W.I.; Yeager, M. Hexagonal assembly of a restricting TRIM5 protein. Proc. Natl. Acad. Sci. USA 2010, 108, 534-539. [CrossRef] [PubMed]

73. Yu, A.; Skorupka, K.A.; Pak, A.J.; Ganser-Pornillos, B.K.; Pornillos, O.; Voth, G.A. TRIM5 $\alpha$ self-assembly and compartmentalization of the HIV-1 viral capsid. Nat. Commun. 2020, 11, 1-10. [CrossRef] [PubMed]

74. Black, L.R.; Aiken, C. TRIM5 $\alpha$ Disrupts the structure of assembled HIV-1 capsid complexes in vitro. J. Virol. 2010, 84, 6564-6569. [CrossRef] [PubMed] 
75. Stremlau, M.; Perron, M.; Lee, M.; Li, Y.; Song, B.; Javanbakht, H.; Diaz-Griffero, F.; Anderson, D.J.; Sundquist, W.I.; Sodroski, J. Specific recognition and accelerated uncoating of retroviral capsids by the TRIM5 restriction factor. Proc. Natl. Acad. Sci. USA 2006, 103, 5514-5519. [CrossRef] [PubMed]

76. Yudina, Z.; Roa, A.; Johnson, R.; Biris, N.; Vieira, D.A.D.S.A.; Tsiperson, V.; Reszka, N.; Taylor, A.B.; Hart, P.J.; Demeler, B.; et al. RING dimerization links higher-order assembly of TRIM5 $\alpha$ to synthesis of K63-linked polyubiquitin. Cell Rep. 2015, 12, 788-797. [CrossRef]

77. Lienlaf, M.; Hayashi, F.; Di Nunzio, F.; Tochio, N.; Kigawa, T.; Yokoyama, S.; Diaz-Griffero, F. Contribution of E3-ubiquitin ligase activity to HIV-1 restriction by TRIM5 rh: Structure of the RING domain of TRIM. J. Virol. 2011, 85, 8725-8737. [CrossRef]

78. Wu, X.; Anderson, J.L.; Campbell, E.M.; Joseph, A.M.; Hope, T.J. Proteasome inhibitors uncouple rhesus TRIM5 restriction of HIV-1 reverse transcription and infection. Proc. Natl. Acad. Sci. USA 2006, 103, 7465-7470. [CrossRef]

79. Rold, C.J.; Aiken, C. Proteasomal degradation of TRIM5 $\alpha$ during retrovirus restriction. PLoS Pathog. 2008, 4, e1000074. [CrossRef]

80. Fletcher, A.J.; Vaysburd, M.; Maslen, S.; Zeng, J.; Skehel, J.M.; Towers, G.J.; James, L.C. Trivalent RING assembly on retroviral capsids activates TRIM5 ubiquitination and innate immune signaling. Cell Host Microbe 2018, 24, 761-775.e6. [CrossRef]

81. Javanbakht, H.; Diaz-Griffero, F.; Stremlau, M.; Si, Z.; Sodroski, J. The contribution of RING and B-box 2 domains to retroviral restriction mediated by monkey TRIM5 $\alpha$. J. Biol. Chem. 2005, 280, 26933-26940. [CrossRef] [PubMed]

82. Sayah, D.M.; Sokolskaja, E.; Berthoux, L.; Luban, J. Cyclophilin A retrotransposition into TRIM5 explains owl monkey resistance to HIV 1. Nature 2004, 430, 569-573. [CrossRef]

83. Luban, J.; Bossolt, K.L.; Franke, E.K.; Kalpana, G.V.; Goff, S.P. Human immunodeficiency virus type 1 Gag protein binds to cyclophilins A and B. Cell 1993, 73, 1067-1078. [CrossRef]

84. Goldstone, D.C.; Yap, M.W.; Robertson, L.E.; Haire, L.F.; Taylor, W.R.; Katzourakis, A.; Stoye, J.P.; Taylor, I.A. Structural and functional analysis of prehistoric lentiviruses uncovers an ancient molecular interface. Cell Host Microbe 2010, 8, 248-259. [CrossRef] [PubMed]

85. Chan, E.; Schaller, T.; Eddaoudi, A.; Zhan, H.; Tan, C.P.; Jacobsen, M.; Thrasher, A.J.; Towers, G.J.; Qasim, W. Lentiviral gene therapy against human immunodeficiency virus type 1, using a novel human TRIM21-cyclophilin A restriction factor. Hum. Gene Ther. 2012, 23, 1176-1185. [CrossRef]

86. Newman, R.M.; Hall, L.; Kirmaier, A.; Pozzi, L.-A.; Pery, E.; Farzan, M.; O’Neil, S.P.; Johnson, W. Evolution of a TRIM5-CypA splice isoform in old world monkeys. PLoS Pathog. 2008, 4, e1000003. [CrossRef] [PubMed]

87. Liu, Z.; Pan, Q.; Liang, Z.; Qiao, W.; Cen, S.; Liang, C. The highly polymorphic cyclophilin A-binding loop in HIV-1 capsid modulates viral resistance to MxB. Retrovirology 2015, 12, 1-6. [CrossRef] [PubMed]

88. Liu, Z.; Pan, Q.; Ding, S.; Qian, J.; Xu, F.; Zhou, J.; Cen, S.; Guo, F.; Liang, C. The interferon-inducible MxB protein inhibits HIV-1 infection. Cell Host Microbe 2013, 14, 398-410. [CrossRef]

89. Javanbakht, H.; Diaz-Griffero, F.; Yuan, W.; Yeung, D.F.; Li, X.; Song, B.; Sodroski, J. The ability of multimerized cyclophilin A to restrict retrovirus infection. Virology 2007, 367, 19-29. [CrossRef]

90. Yoo, S.; Myszka, D.G.; Yeh, C.-Y.; McMurray, M.; Hill, C.P.; Sundquist, W.I. Molecular recognition in the HIV-1 capsid/cyclophilin A complex. J. Mol. Biol. 1997, 269, 780-795. [CrossRef]

91. Wagner, J.M.; Christensen, D.E.; Bhattacharya, A.; Dawidziak, D.M.; Roganowicz, M.D.; Wan, Y.; Pumroy, R.A.; Demeler, B.; Ivanov, D.N.; Ganser-Pornillos, B.K.; et al. A general model for retroviral capsid pattern recognition by TRIM5 proteins. J. Virol. 2018, 92, e01563-17. [CrossRef]

92. Price, A.J.; Marzetta, F.; Lammers, M.; Ylinen, L.M.J.; Schaller, T.; Wilson, S.J.; Towers, G.J.; James, L.C. Active site remodeling switches HIV specificity of antiretroviral TRIMCyp. Nat. Struct. Mol. Biol. 2009, 16, 1036-1042. [CrossRef]

93. Ganser-Pornillos, B.K.; Pornillos, O. Restriction of HIV-1 and other retroviruses by TRIM5. Nat. Rev. Genet. 2019, 17, 546-556. [CrossRef]

94. Perron, M.J.; Stremlau, M.; Song, B.; Ulm, W.; Mulligan, R.C.; Sodorski, J. TRIM5 $\alpha$ mediates the postentry block to N-tropic murine leukemia viruses in human cells. Proc. Natl. Acad. Sci. USA 2004, 101, 11827-11832. [CrossRef] [PubMed]

95. Sawyer, S.L.; Wu, L.I.; Akey, J.M.; Emerman, M.; Malik, H.S. High-frequency persistence of an impaired allele of the retroviral defense gene TRIM5 $\alpha$ in humans. Curr. Biol. 2006, 16, 95-100. [CrossRef] [PubMed]

96. Ohkura, S.; Yap, M.W.; Sheldon, T.; Stoye, J.P. All three variable regions of the TRIM $5 \alpha$ B30.2 domain can contribute to the specificity of retrovirus restriction. J. Virol. 2006, 80, 8554-8565. [CrossRef] [PubMed]

97. Pham, Q.T.; Bouchard, A.; Grütter, M.G.; Berthoux, L. Generation of human TRIM5 $\alpha$ mutants with high HIV-1 restriction activity. Gene Ther. 2010, 17, 859-871. [CrossRef] [PubMed]

98. Richardson, M.W.; Guo, L.; Xin, F.; Yang, X.; Riley, J.L. Stabilized human TRIM5 $\alpha$ protects human T cells from HIV-1 infection. Mol. Ther. 2014, 22, 1084-1095. [CrossRef] [PubMed]

99. Li, Y.; Li, X.; Stremlau, M.; Lee, M.; Sodroski, J. Removal of arginine 332 allows human TRIM5 $\alpha$ to bind human immunodeficiency virus capsids and to restrict infection. J. Virol. 2006, 80, 6738-6744. [CrossRef]

100. OhAinle, M.; Helms, L.; Vermeire, J.; Roesch, F.; Humes, D.; Basom, R.; Delrow, J.J.; Overbaugh, J.; Emerman, M. A viruspackageable CRISPR screen identifies host factors mediating interferon inhibition of HIV. eLife 2018, 7. [CrossRef]

101. Lu, K.; den Brave, F.; Jentsch, S. Receptor oligomerization guides pathway choice between proteasomal and autophagic degradation. Nat. Cell Biol. 2017, 19, 732-739. [CrossRef]

102. Shaid, S.; Brandts, C.H.; Serve, H.; Dikic, I. Ubiquitination and selective autophagy. Cell Death Differ. 2012, 20, 21-30. [CrossRef] 
103. Rajalingam, K.; Dikic, I. Expanding the ubiquitin code. Cell 2016, 164, 1074-1074.e1. [CrossRef] [PubMed]

104. Li, X.; Elmira, E.; Rohondia, S.; Wang, J.; Liu, J.; Dou, Q.P. A patent review of the ubiquitin ligase system: 2015-2018. Expert Opin. Ther. Patents 2018, 28, 919-937. [CrossRef]

105. Seissler, T.; Marquet, R.; Paillart, J.C. Hijacking of the ubiquitin/proteasome pathway by the hiv auxiliary proteins. Viruses 2017, 9, 322. [CrossRef] [PubMed]

106. Metzger, M.B.; Pruneda, J.N.; Klevit, R.E.; Weissman, A.M. RING-type E3 ligases: Master manipulators of E2 ubiquitin-conjugating enzymes and ubiquitination. Biochim. Biophys. Acta (BBA) Bioenerg. 2014, 1843, 47-60. [CrossRef]

107. Tai, H.-C.; Schuman, E.M. Ubiquitin, the proteasome and protein degradation in neuronal function and dysfunction. Nat. Rev. Neurosci. 2008, 9, 826-838. [CrossRef] [PubMed]

108. Ghosh, R.; Vinod, V.; Simons, J.D.; Boudina, S. Protein and mitochondria quality control mechanisms and cardiac aging. Cells 2020, 9, 933. [CrossRef]

109. Rojas, V.K.; Park, I.-W. Role of the ubiquitin proteasome system (UPS) in the HIV-1 life cycle. Int. J. Mol. Sci. 2019, 20, 2984. [CrossRef] [PubMed]

110. Lennemann, N.J.; Coyne, C.B. Catch me if you can: The link between autophagy and viruses. PLoS Pathog. 2015, 11, e1004685. [CrossRef]

111. Dikic, I. Proteasomal and autophagic degradation systems. Annu. Rev. Biochem. 2017, 86, 193-224. [CrossRef]

112. Russell, R.C.; Tian, Y.; Yuan, H.; Park, H.W.; Chang, Y.-Y.; Kim, J.; Kim, H.; Neufeld, T.P.; Dillin, A.; Guan, K.-L. ULK1 induces autophagy by phosphorylating Beclin-1 and activating VPS34 lipid kinase. Nat. Cell Biol. 2013, 15, 741-750. [CrossRef]

113. Kim, J.; Kundu, M.; Viollet, B.; Guan, K.-L. AMPK and mTOR regulate autophagy through direct phosphorylation of Ulk1. Nat. Cell Biol. 2011, 13, 132-141. [CrossRef]

114. Agrotis, A.; Ketteler, R. On ATG4B as drug target for treatment of solid tumours-The knowns and the unknowns. Cells 2019, 9, 53. [CrossRef] [PubMed]

115. Hanada, T.; Noda, N.N.; Satomi, Y.; Ichimura, Y.; Fujioka, Y.; Takao, T.; Inagaki, F.; Ohsumi, Y. The Atg12-Atg5 conjugate has a novel E3-like activity for protein lipidation in autophagy. J. Biol. Chem. 2007, 282, 37298-37302. [CrossRef]

116. Noda, N.N.; Fujioka, Y.; Hanada, T.; Ohsumi, Y.; Inagaki, F. Structure of the Atg12-Atg5 conjugate reveals a platform for stimulating Atg8-PE conjugation. EMBO Rep. 2013, 14, 206-211. [CrossRef] [PubMed]

117. Kimura, T.; Jia, J.; Claude-Taupin, A.; Kumar, S.; Choi, S.W.; Gu, Y.; Mudd, M.; Dupont, N.; Jiang, S.; Peters, R.; et al. Cellular and molecular mechanism for secretory autophagy. Autophagy 2017, 13, 1084-1085. [CrossRef]

118. He, C.; Klionsky, D.J. Regulation mechanisms and signaling pathways of autophagy. Annu. Rev. Genet. 2009, 43, 67-93. [CrossRef]

119. Deretic, V.; Saitoh, T.; Akira, S. Autophagy in infection, inflammation and immunity. Nat. Rev. Immunol. 2013, 13, $722-737$. [CrossRef] [PubMed]

120. Gump, J.M.; Thorburn, A. Sorting cells for basal and induced autophagic flux by quantitative ratiometric flow cytometry. Autophagy 2014, 10, 1327-1334. [CrossRef]

121. Svenning, S.; Johansen, T. Selective autophagy. Essays Biochem. 2013, 55, 79-92. [CrossRef]

122. Szalai, P.; Hagen, L.K.; Sætre, F.; Luhr, M.; Sponheim, M.; Øverbye, A.; Mills, I.G.; Seglen, P.O.; Engedal, N. Autophagic bulk sequestration of cytosolic cargo is independent of LC3, but requires GABARAPs. Exp. Cell Res. 2015, 333, 21-38. [CrossRef] [PubMed]

123. Pankiv, S.; Clausen, T.H.; Lamark, T.; Brech, A.; Bruun, J.-A.; Outzen, H.; Øvervatn, A.; Bjørkøy, G.; Johansen, T. p62/SQSTM1 binds directly to Atg8/LC3 to facilitate degradation of ubiquitinated protein aggregates by autophagy. J. Biol. Chem. 2007, 282, 24131-24145. [CrossRef] [PubMed]

124. Keown, J.R.; Black, M.M.; Ferron, A.; Yap, M.W.; Barnett, M.J.; Pearce, F.G.; Stoye, J.P.; Goldstone, D.C. A helical LC3-interacting region mediates the interaction between the retroviral restriction factor Trim $5 \alpha$ and mammalian autophagy-related ATG8 proteins. J. Biol. Chem. 2018, 293, 18378-18386. [CrossRef] [PubMed]

125. Kimura, T.; Mandell, M.; Deretic, V. Precision autophagy directed by receptor regulators-Emerging examples within the TRIM family. J. Cell Sci. 2016, 129, 881-891. [CrossRef]

126. Fletcher, A.J.; Christensen, D.E.; Nelson, C.; Tan, C.P.; Schaller, T.; Lehner, P.J.; Sundquist, W.I.; Towers, G.J. TRIM $5 \alpha$ requires Ube2W to anchor Lys63-linked ubiquitin chains and restrict reverse transcription. EMBO J. 2015, 34, 2078-2095. [CrossRef]

127. Yamauchi, K.; Wada, K.; Tanji, K.; Tanaka, M.; Kamitani, T. Ubiquitination of E3 ubiquitin ligase TRIM $5 \alpha$ and its potential role. FEBS J. 2008, 275, 1540-1555. [CrossRef]

128. Perez-Caballero, D.; Hatziioannou, T.; Zhang, F.; Cowan, S.; Bieniasz, P.D. Restriction of human immunodeficiency virus type 1 by TRIM-CypA occurs with rapid kinetics and independently of cytoplasmic bodies, ubiquitin, and proteasome activity. J. Virol. 2005, 79, 15567-15572. [CrossRef]

129. Mandell, M.A.; Jain, A.; Arko-Mensah, J.; Chauhan, S.; Kimura, T.; Dinkins, C.; Silvestri, G.; Münch, J.; Kirchhoff, F.; Simonsen, A.; et al. TRIM proteins regulate autophagy and can target autophagic substrates by direct recognition. Dev. Cell 2014, 30, 394-409. [CrossRef]

130. Lebovitz, C.B.; DeVorkin, L.; Bosc, D.G.; Rothe, K.; Singh, J.; Bally, M.B.; Jiang, X.; Young, R.N.; Lum, J.J.; Gorski, S.M. Precision autophagy: Will the next wave of selective autophagy markers and specific autophagy inhibitors feed clinical pipelines? Autophagy 2015, 11, 1949-1952. [CrossRef] 
131. Di Rienzo, M.; Romagnoli, A.; Antonioli, M.; Piacentini, M.; Fimia, G.M. TRIM proteins in autophagy: Selective sensors in cell damage and innate immune responses. Cell Death Differ. 2020, 27, 887-902. [CrossRef] [PubMed]

132. Kimura, T.; Jain, A.; Choi, S.W.; Mandell, M.A.; Schroder, K.; Johansen, T.; Deretic, V. TRIM-mediated precision autophagy targets cytoplasmic regulators of innate immunity. J. Cell Biol. 2015, 210, 973-989. [CrossRef]

133. Imam, S.; Talley, S.; Nelson, R.S.; Dharan, A.; O'Connor, C.; Hope, T.J.; Campbell, E.M. TRIM5 $\alpha$ degradation via autophagy is not required for retroviral restriction. J. Virol. 2016, 90, 3400-3410. [CrossRef] [PubMed]

134. Carter, S.D.; Mamede, J.I.; Hope, T.J.; Jensen, G.J. Correlated cryogenic fluorescence microscopy and electron cryo-tomography shows that exogenous TRIM5 $\alpha$ can form hexagonal lattices or autophagy aggregates in vivo. Proc. Natl. Acad. Sci. USA 2020, 117, 29702-29711. [CrossRef] [PubMed]

135. Sardiello, M.; Cairo, S.; Fontanella, B.; Ballabio, A.; Meroni, G. Genomic analysis of the TRIM family reveals two groups of genes with distinct evolutionary properties. BMC Evol. Biol. 2008, 8, 225. [CrossRef] [PubMed]

136. De Witte, L.; Nabatov, A.; Pion, M.; Fluitsma, D.; De Jong, M.A.W.P.; De Gruijl, T.; Piguet, V.; Van Kooyk, Y.; Geijtenbeek, T.B.H. Langerin is a natural barrier to HIV-1 transmission by Langerhans cells. Nat. Med. 2007, 13, 367-371. [CrossRef]

137. Ribeiro, C.M.S.; Sarrami-Forooshani, R.; Geijtenbeek, T.B.H. HIV-1 border patrols: Langerhans cells control antiviral responses and viral transmission. Future Virol. 2015, 10, 1231-1243. [CrossRef]

138. Hladik, F.; Sakchalathorn, P.; Ballweber, L.; Lentz, G.; Fialkow, M.; Eschenbach, D.; McElrath, M.J. Initial events in establishing vaginal entry and infection by human immunodeficiency virus type-1. Immunology 2007, 26, 257-270. [CrossRef] [PubMed]

139. Kawamura, T.; Qualbani, M.; Thomas, E.K.; Orenstein, J.M.; Blauvelt, A. Low levels of productive HIV infection in Langerhans cell-like dendritic cells differentiated in the presence of TGF- $\beta 1$ and increased viral replication with CD40 ligand-induced maturation. Eur. J. Immunol. 2001, 31, 360-368. [CrossRef]

140. Valladeau, J.; Ravel, O.; Dezutter-Dambuyant, C.; Moore, K.; Kleijmeer, M.; Liu, Y.; Duvert-Frances, V.; Vincent, C.; Schmitt, D.; Davoust, J.; et al. Langerin, a novel C-type lectin specific to Langerhans cells, is an endocytic receptor that induces the formation of Birbeck granules. Immunity 2000, 12, 71-81. [CrossRef]

141. Van Der Vlist, M.; Geijtenbeek, T.B.H. Langerin functions as an antiviral receptor on Langerhans cells. Immunol. Cell Biol. 2010, 88, 410-415. [CrossRef]

142. Berg, L.M.V.D.; Ribeiro, C.M.S.; Zijlstra-Willems, E.M.; De Witte, L.; Fluitsma, D.; Tigchelaar, W.; Everts, V.; Geijtenbeek, T.B.H. Caveolin-1 mediated uptake via langerin restricts HIV-1 infection in human Langerhans cells. Retrovirology 2014, 11, 1-9. [CrossRef]

143. Czubala, M.A.; Finsterbusch, K.; Ivory, M.O.; Mitchell, J.P.; Ahmed, Z.; Shimauchi, T.; Karoo, R.O.; Coulman, S.A.; Gateley, C.; Birchall, J.C.; et al. TGF $\beta$ Induces a SAMHD1-independent post-entry restriction to HIV-1 infection of human epithelial langerhans cells. J. Investig. Dermatol. 2016, 136, 1981-1989. [CrossRef] [PubMed]

144. Hertoghs, N.; Geijtenbeek, T.B.H.; Ribeiro, C.M.S. Interplay between HIV-1 innate sensing and restriction in mucosal dendritic cells: Balancing defense and viral transmission. Curr. Opin. Virol. 2017, 22, 112-119. [CrossRef] [PubMed]

145. Sakoh-Nakatogawa, M.; Matoba, K.; Asai, E.; Kirisako, H.; Ishii, J.; Noda, N.N.; Inagaki, F.; Nakatogawa, H.; Ohsumi, Y. Atg12-Atg5 conjugate enhances E2 activity of Atg3 by rearranging its catalytic site. Nat. Struct. Mol. Biol. 2013, 20, 433-439. [CrossRef]

146. Walczak, M.; Martens, S. Dissecting the role of the Atg12-Atg5-Atg16 complex during autophagosome formation. Autophagy 2013, 9, 424-425. [CrossRef]

147. Gramberg, T.; Soilleux, E.; Fisch, T.; Lalor, P.F.; Hofmann, H.; Wheeldon, S.; Cotterill, A.; Wegele, A.; Winkler, T.; Adams, D.H.; et al. Interactions of LSECtin and DC-SIGN/DC-SIGNR with viral ligands: Differential $\mathrm{pH}$ dependence, internalization and virion binding. Virology 2008, 373, 189-201. [CrossRef]

148. Trifonova, R.T.; Bollman, B.; Barteneva, N.S.; Lieberman, J. Myeloid cells in intact human cervical explants capture HIV and can transmit it to CD4 T cells. Front. Immunol. 2018, 9, 2719. [CrossRef]

149. Bertram, K.M.; Botting, R.A.; Baharlou, H.; Rhodes, J.W.; Rana, H.; Graham, J.D.; Patrick, E.; Fletcher, J.; Plasto, T.M.; Truong, N.R.; et al. Identification of HIV transmitting CD11c+ human epidermal dendritic cells. Nat. Commun. 2019, 10, 1-15. [CrossRef]

150. Mcllroy, D.; Autran, B.; Cheynier, R.; Wain-Hobson, S.; Clauvel, J.P.; Oksenhendler, E.; Debré, P.; Hosmalin, A. Infection frequency of dendritic cells and CD4+ T lymphocytes in spleens of human immunodeficiency virus-positive patients. J. Virol. 1995, 69, 4737-4745. [CrossRef] [PubMed]

151. Gringhuis, S.I.; Van Der Vlist, M.; Berg, L.M.V.D.; Dunnen, J.D.; Litjens, M.; Geijtenbeek, T.B.H. HIV-1 exploits innate signaling by TLR8 and DC-SIGN for productive infection of dendritic cells. Nat. Immunol. 2010, 11, 419-426. [CrossRef]

152. Geijtenbeek, T.B.; Kwon, D.S.; Torensma, R.; Van Vliet, S.J.; Van Duijnhoven, G.C.; Middel, J.; Cornelissen, I.L.; Nottet, H.S.; KewalRamani, V.N.; Littman, D.R.; et al. DC-SIGN, a dendritic cell-specific HIV-1-binding protein that enhances trans-infection of T cells. Cell 2000, 100, 587-597. [CrossRef]

153. Blanchet, F.P.; Moris, A.; Nikolic, D.S.; Lehmann, M.; Cardinaud, S.; Stalder, R.; Garcia, E.; Dinkins, C.; Leuba, F.; Wu, L.; et al. Human immunodeficiency virus-1 inhibition of immunoamphisomes in dendritic cells impairs early innate and adaptive immune responses. Immunity 2010, 32, 654-669. [CrossRef] [PubMed]

154. Hertoghs, N.; Nijmeijer, B.M.; Van Teijlingen, N.H.; Fenton-May, A.E.; Kaptein, T.M.; Van Hamme, J.L.; Kappes, J.C.; Kootstra, N.A.; Hahn, B.H.; Borrow, P.; et al. Sexually transmitted founder HIV-1 viruses are relatively resistant to Langerhans cell-mediated restriction. PLoS ONE 2019, 14, e0226651. [CrossRef] 
155. De Jong, M.A.; de Witte, L.; Oudhoff, M.J.; Gringhuis, S.I.; Gallay, P.; Geijtenbeek, T.B. TNF- $\alpha$ and TLR agonists increase susceptibility to HIV-1 transmission by human Langerhans cells ex vivo. J. Clin. Investig. 2008, 118, 3440-3452. [CrossRef]

156. Hester, R.A.; Kennedy, S.B. Candida infection as a risk factor for HIV transmission. J. Women's Health 2003, 12, 487-494. [CrossRef]

157. Fleming, D.T.; Wasserheit, J.N. From epidemiological synergy to public health policy and practice: The contribution of other sexually transmitted diseases to sexual transmission of HIV infection. Sex. Transm. Infect. 1999, 75, 3-17. [CrossRef]

158. Engering, A.; Geijtenbeek, T.B.; van Vliet, S.J.; Wijers, M.; van Liempt, E.; Demaurex, N.; Lanzavecchia, A.; Fransen, J.; Figdor, C.G.; Piguet, V.; et al. The dendritic cell-specific adhesion receptor DC-SIGN internalizes antigen for fresentation to T cells. J. Immunol. 2002, 168, 2118-2126. [CrossRef] [PubMed]

159. Cameron, P.U.; Freudenthal, P.S.; Barker, J.M.; Gezelter, S.; Inaba, K.; Steinman, R.M. Dendritic cells exposed to human immunodeficiency virus type- 1 transmit a vigorous cytopathic infection to CD4+ T cells. Science 1992, 257, 383-387. [CrossRef] [PubMed]

160. Pope, M.; Betjes, M.; Romani, N.; Hirmand, H.; Cameron, P.; Hoffman, L.; Gezelter, S.; Schuler, G.; Steinman, R. Conjugates of dendritic cells and memory T lymphocytes from skin facilitate productive infection with HIV-1. Cell 1994, 78, 389-398. [CrossRef]

161. Smed-Sörensen, A.; Loré, K.; Vasudevan, J.; Louder, M.K.; Andersson, J.; Mascola, J.R.; Spetz, A.-L.; Koup, R.A. Differential susceptibility to human immunodeficiency virus type 1 infection of myeloid and plasmacytoid dendritic cells. J. Virol. 2005, 79, 8861-8869. [CrossRef]

162. Gringhuis, S.I.; den Dunnen, J.; Litjens, M.; van Het Hof, B.; van Kooyk, Y.; Geijtenbeek, T.B. C-type lectin DC-SIGN modulates toll-like receptor signaling via Raf-1 kinase-dependent acetylation of transcription factor NF-kB. Immunity 2007, 26, 605-616. [CrossRef]

163. Gringhuis, S.I.; Dunnen, J.D.; Litjens, M.; Van Der Vlist, M.; Geijtenbeek, T.B.H. Carbohydrate-specific signaling through the DC-SIGN signalosome tailors immunity to Mycobacterium tuberculosis, HIV-1 and Helicobacter pylori. Nat. Immunol. 2009, 10, 1081-1088. [CrossRef]

164. Cloherty, A.P.M.; van Teijlingen, N.H.; Eisden, T.T.H.D.; van Hamme, J.L.; Rader, A.G.; Geijtenbeek, T.B.H.; Schreurs, R.R.C.E.; Ribeiro, C.M.S. Autophagy-enhancing drugs limit mucosal HIV-1 acquisition and suppress viral replication ex vivo. Sci. Rep. 2021, 11, 4767. PMCID: PMC7910550. [CrossRef] [PubMed]

165. Kim, K.; Dauphin, A.; Komurlu, S.; McCauley, S.M.; Yurkovetskiy, L.; Carbone, C.; Diehl, W.E.; Strambio-De-Castillia, C.; Campbell, E.M.; Luban, J. Cyclophilin A protects HIV-1 from restriction by human TRIM5 $\alpha$. Nat. Microbiol. 2019, 4, $2044-2051$. [CrossRef] [PubMed]

166. Thali, M.; Bukovsky, A.A.; Kondo, E.; Rosenwlrth, B.; Walsh, C.T.; Sodroski, J.; Göttlinger, H.G. Functional association of cyclophilin A with HIV-1 virions. Nature 1994, 372, 363-365. [CrossRef]

167. Gamble, T.R.; Vajdos, F.F.; Yoo, S.; Worthylake, D.K.; Houseweart, M.; Sundquist, W.I.; Hill, C.P. Crystal structure of human cyclophilin A bound to the amino-terminal domain of HIV-1 capsid. Cell 1996, 87, 1285-1294. [CrossRef]

168. Jin, C.; Li, J.; Cheng, L.; Liu, F.; Wu, N. Gp120 binding with DC-SIGN induces reactivation of HIV-1 provirus via the NF- $\kappa \mathrm{B}$ signaling pathway. Acta Biochim. Biophys. Sin. 2015, 48, 275-281. [CrossRef]

169. Arhel, N.J.; Nisole, S.; Carthagena, L.; Coutant, F.; Souque, P.; Brussel, A.; Estaquier, J.; Charneau, P. Lack of endogenous TRIM5 $\alpha$-mediated restriction in rhesus macaque dendritic cells. Blood 2008, 112, 3772-3776. [CrossRef]

170. Sattentau, Q.J.; Stevenson, M. Macrophages and HIV-1: An unhealthy constellation. Cell Host Microbe 2016, 19, 304-310. [CrossRef]

171. Haldar, M.; Murphy, K.M. Origin, development, and homeostasis of tissue-resident macrophages. Immunol. Rev. 2014, 262, 25-35. [CrossRef] [PubMed]

172. Hirayama, D.; Iida, T.; Nakase, H. The phagocytic function of macrophage-enforcing innate immunity and tissue homeostasis. Int. J. Mol. Sci. 2017, 19, 92. [CrossRef]

173. Lopez, P.; Koh, W.H.; Hnatiuk, R.; Murooka, T.T. HIV infection stabilizes macrophage-T cell interactions to promote cell-cell HIV spread. J. Virol. 2019, 93, 805-819. [CrossRef]

174. Carr, J.; Hocking, H.; Li, P.; Burrell, C. Rapid and efficient cell-to-cell transmission of human immunodeficiency virus infection from monocyte-derived macrophages to peripheral blood lymphocytes. Virology 1999, 265, 319-329. [CrossRef]

175. Duncan, C.J.A.; Russell, R.A.; Sattentau, Q.J. High multiplicity HIV-1 cell-to-cell transmission from macrophages to CD4+ T cells limits antiretroviral efficacy. AIDS 2013, 27, 2201-2206. [CrossRef]

176. Kyei, G.B.; Dinkins, C.; Davis, A.S.; Roberts, E.; Singh, S.B.; Dong, C.; Wu, L.; Kominami, E.; Ueno, T.; Yamamoto, A.; et al. Autophagy pathway intersects with HIV-1 biosynthesis and regulates viral yields in macrophages. J. Cell Biol. 2009, 186, 255-268. [CrossRef] [PubMed]

177. Sagnier, S.; Daussy, C.F.; Borel, S.; Robert-Hebmann, V.; Faure, M.; Blanchet, F.P.; Beaumelle, B.; Biard-Piechaczyk, M.; Espert, L. Autophagy restricts HIV-1 infection by selectively degrading TAT in CD4+T lymphocytes. J. Virol. 2015, 89, 615-625. [CrossRef]

178. Campbell, G.R.; Rawat, P.; Bruckman, R.S.; Spector, S.A. Human immunodeficiency virus type 1 Nef inhibits autophagy through transcription factor EB sequestration. PLoS Pathog. 2015, 11, e1005018. [CrossRef] [PubMed]

179. Di Malta, C.; Cinque, L.; Settembre, C. Transcriptional regulation of autophagy: Mechanisms and diseases. Front. Cell Dev. Biol. 2019, 7, 114. [CrossRef] [PubMed]

180. Chang, C.; Young, L.N.; Morris, K.L.; Von Bülow, S.; Schöneberg, J.; Yamamoto-Imoto, H.; Oe, Y.; Yamamoto, K.; Nakamura, S.; Stjepanovic, G.; et al. Bidirectional control of autophagy by BECN1 BARA domain dynamics. Mol. Cell 2019, 73, 339-353.e6. [CrossRef] [PubMed] 
181. Castro-Gonzalez, S.; Shi, Y.; Colomer-Lluch, M.; Song, Y.; Mowery, K.; Almodovar, S.; Bansal, A.; Kirchhoff, F.; Sparrer, K.; Liang, C.; et al. HIV-1 Nef counteracts autophagy restriction by enhancing the association between BECN1 and its inhibitor BCL2 in a PRKN-dependent manner. Autophagy 2020, 1-25. [CrossRef]

182. Veillette, M.; Bichel, K.; Pawlica, P.; Freund, S.M.V.; Plourde, M.B.; Pham, Q.T.; Reyes-Moreno, C.; James, L.C.; Berthoux, L. The V86M mutation in HIV-1 capsid confers resistance to TRIM5 $\alpha$ by abrogation of cyclophilin a-dependent restriction and enhancement of viral nuclear import. Retrovirology 2013, 10, 25. [CrossRef]

183. Trifonova, R.T.; Lieberman, J.; Van Baarle, D. Distribution of immune cells in the human cervix and implications for HIV transmission. Am. J. Reprod. Immunol. 2014, 71, 252-264. [CrossRef]

184. Borel, S.; Robert-Hebmann, V.; AlFaisal, J.; Jain, A.; Faure, M.; Espert, L.; Chaloin, L.; Paillart, J.-C.; Johansen, T.; Biard-Piechaczyk, M. HIV-1 viral infectivity factor interacts with microtubule-associated protein light chain 3 and inhibits autophagy. AIDS 2015, 29, 275-286. [CrossRef]

185. Sanfridson, A.; Hester, S.; Doyle, C. Nef proteins encoded by human and simian immunodeficiency viruses induce the accumulation of endosomes and lysosomes in human T cells. Proc. Natl. Acad. Sci. USA 1997, 94, 873-878. [CrossRef] [PubMed]

186. Volkmann, B.; Wittmann, S.; Lagisquet, J.; Deutschmann, J.; Eissmann, K.; Ross, J.J.; Biesinger, B.; Gramberg, T. Human TRIM5 $\alpha$ senses and restricts LINE-1 elements. Proc. Natl. Acad. Sci. USA 2020, 117, 17965-17976. [CrossRef] [PubMed]

187. Baldauf, H.-M.; Pan, X.; Erikson, E.; Schmidt, S.; Daddacha, W.; Burggraf, M.; Schenkova, K.; Ambiel, I.; Wabnitz, G.H.; Gramberg, T.; et al. SAMHD1 restricts HIV-1 infection in resting CD4+ T cells. Nat. Med. 2012, 18, 1682-1688. [CrossRef] [PubMed]

188. Waheed, A.A.; Swiderski, M.; Khan, A.; Gitzen, A.; Majadly, A.; Freed, E.O. The viral protein U (VPU)-interacting host protein ATP6V0C down-regulates cell-surface expression of tetherin and thereby contributes to HIV-1 release. J. Biol. Chem. 2020, 295, 7327-7340. [CrossRef]

189. Blanchet, F.P.; Mitchell, J.P.; Piguet, V. Beta-TrCP dependency of HIV-1 VPU-induced downregulation of CD4 and BST-2/Tetherin. Curr. HIV Res. 2012, 10, 307-314. [CrossRef]

190. Miyakawa, K.; Ryo, A.; Murakami, T.; Ohba, K.; Yamaoka, S.; Fukuda, M.; Guatelli, J.; Yamamoto, N. BCA2/Rabring7 promotes tetherin-dependent HIV-1 restriction. PLoS Pathog. 2009, 5, e1000700. [CrossRef] [PubMed]

191. Zou, J.; Li, W.; Misra, A.; Yue, F.; Song, K.; Chen, Q.; Guo, G.; Yi, J.; Kimata, J.T.; Liu, L. The viral restriction factor tetherin prevents leucine-rich pentatricopeptide repeat-containing protein (LRPPRC) from association with beclin 1 and B-cell CLL/lymphoma 2 (Bcl-2) and enhances autophagy and mitophagy. J. Biol. Chem. 2015, 290, 7269-7279. [CrossRef]

192. Jin, S.; Tian, S.; Luo, M.; Xie, W.; Liu, T.; Duan, T.; Wu, Y.; Cui, J. Tetherin suppresses type I interferon signaling by targeting MAVS for NDP52-mediated selective autophagic degradation in human cells. Mol. Cell 2017, 68, 308-322.e4. [CrossRef]

193. Tareen, S.U.; Emerman, M. Human Trim $5 \alpha$ has additional activities that are uncoupled from retroviral capsid recognition. Virology 2011, 409, 113-120. [CrossRef] [PubMed]

194. Saha, B.; Chisholm, D.; Kell, A.M.; Mandell, M.A. A non-canonical role for the autophagy machinery in anti-retroviral signaling mediated by TRIM5 $\alpha$. PLoS Pathog. 2020, 16, e1009017. [CrossRef]

195. Cheney, K.M.; McKnight, Á. Interferon-alpha mediates restriction of human immunodeficiency virus type-1 replication in primary human macrophages at an early stage of replication. PLoS ONE 2010, 5, e13521. [CrossRef] [PubMed]

196. Barr, S.D.; Smiley, J.R.; Bushman, F.D. The interferon response inhibits HIV particle production by induction of TRIM22. PLoS Pathog. 2008, 4, e1000007. [CrossRef] [PubMed]

197. Chen, K.; Huang, J.; Zhang, C.; Huang, S.; Nunnari, G.; Wang, F.-X.; Tong, X.; Gao, L.; Nikisher, K.; Zhang, H. Alpha interferon potently enhances the anti-human immunodeficiency virus type 1 activity of APOBEC3G in resting primary CD4 T Cells. J. Virol. 2006, 80, 7645-7657. [CrossRef]

198. Iwasaki, A. Innate immune recognition of HIV-1. Immunity 2012, 37, 389-398. [CrossRef]

199. Lascano, J.; Uchil, P.D.; Mothes, W.; Luban, J. TRIM5 retroviral restriction activity correlates with the ability to induce innate immune signaling. J. Virol. 2015, 90, 308-316. [CrossRef] [PubMed]

200. Javanbakht, H.; An, P.; Gold, B.; Petersen, D.C.; O’Huigin, C.; Nelson, G.W.; O’Brien, S.J.; Kirk, G.D.; Detels, R.; Buchbinder, S.; et al. Effects of human TRIM $5 \alpha$ polymorphisms on antiretroviral function and susceptibility to human immunodeficiency virus infection. Virology 2006, 354, 15-27. [CrossRef] [PubMed]

201. Price, H.; Lacap, P.; Tuff, J.; Wachihi, C.; Kimani, J.; Ball, T.B.; Luo, M.; Plummer, F.A. A TRIM $5 \alpha$ exon 2 polymorphism is associated with protection from HIV-1 infection in the Pumwani sex worker cohort. AIDS 2010, 24, 1813-1821. [CrossRef] [PubMed]

202. Da Silva, R.C.; Coelho, A.V.C.; Arraes, L.C.; Brandão, L.A.C.; Crovella, S.; Guimarães, R.L. TRIM5 gene polymorphisms in HIV-1-infected patients and healthy controls from Northeastern Brazil. Immunol. Res. 2016, 64, 1237-1242. [CrossRef]

203. Speelmon, E.C.; Livingston-Rosanoff, D.; Li, S.S.; Vu, Q.; Bui, J.; Geraghty, D.E.; Zhao, L.P.; McElrath, M.J. Genetic association of the antiviral restriction factor TRIM5 $\alpha$ with human immunodeficiency virus type 1 infection. J. Virol. 2006, 80, $2463-2471$. [CrossRef]

204. Nakajima, T.; Nakayama, E.E.; Kaur, G.; Terunuma, H.; Mimaya, J.-I.; Ohtani, H.; Mehra, N.; Shioda, T.; Kimura, A. Impact of novel TRIM5 $\alpha$ variants, Gly110Arg and G176del, on the anti-HIV-1 activity and the susceptibility to HIV-1 infection. AIDS 2009, 23, 2091-2100. [CrossRef]

205. Liu, F.-L.; Qiu, Y.-Q.; Li, H.; Kuang, Y.-Q.; Tang, X.; Cao, G.; Tang, N.L.S.; Zheng, Y.-T. An HIV-1 resistance polymorphism in TRIM5 $\alpha$ gene among chinese intravenous drug users. J. Acquir. Immune Defic. Syndr. (JAIDS) 2011, 56, 306-311. [CrossRef] 
206. Van Manen, D.; Rits, M.A.N.; Beugeling, C.; Van Dort, K.; Schuitemaker, H.; Kootstra, N.A. The effect of Trim5 polymorphisms on the clinical course of HIV-1 infection. PLoS Pathog. 2008, 4, e18. [CrossRef]

207. Nakayama, E.E.; Nakajima, T.; Kaur, G.; Mimaya, J.-I.; Terunuma, H.; Mehra, N.; Kimura, A.; Shioda, T. A naturally occurring single amino acid substitution in human TRIM5 $\alpha$ linker region affects its anti-HIV type 1 activity and susceptibility to HIV type 1 infection. AIDS Res. Hum. Retrovir. 2013, 29, 919-924. [CrossRef] [PubMed]

208. Singh, H.; Samani, D.; Ghate, M.V.; Gangakhedkar, R.R. Impact of cellular restriction gene (TRIM5 $\alpha$, BST-2) polymorphisms on the acquisition of HIV-1 and disease progression. J. Gene Med. 2018, 20, e3004. [CrossRef]

209. Ovsyannikova, I.G.; Haralambieva, I.H.; Dhiman, N.; O’Byrne, M.M.; Pankratz, V.S.; Jacobson, R.M.; Poland, G.A. Polymorphisms in the vitamin A receptor and innate immunity genes influence the antibody response to rubella vaccination. J. Infect. Dis. 2010, 201, 207-213. [CrossRef] [PubMed]

210. Ovsyannikova, I.G.; Haralambieva, I.H.; Vierkant, R.A.; O’Byrne, M.M.; Poland, G.A. Associations between polymorphisms in the antiviral TRIM genes and measles vaccine immunity. Hum. Immunol. 2013, 74, 768-774. [CrossRef] [PubMed]

211. Mobasheri, S.; Irani, N.; Sepahi, A.A.; Sakhaee, F.; Jamnani, F.R.; Vaziri, F.; Siadat, S.D.; Fateh, A. Evaluation of TRIM5 and TRIM22 polymorphisms on treatment responses in Iranian patients with chronic hepatitis C virus infection. Gene 2018, 676, 95-100. [CrossRef]

212. Medrano, L.M.; Rallón, N.; Berenguer, J.; Jiménez-Sousa, M.Á.; Soriano, V.; Aldámiz-Echevarria, T.; Fernández-Rodríguez, A.; García, M.; Tejerina, F.; Martinez, I.; et al. Relationship of TRIM5 and TRIM22 polymorphisms with liver disease and HCV clearance after antiviral therapy in HIV/HCV coinfected patients. J. Transl. Med. 2016, 14, 257. [CrossRef]

213. Abdel-Mohsen, M.; Wang, C.; Strain, M.C.; Lada, S.M.; Deng, X.; Cockerham, L.R.; Pilcher, C.D.; Hecht, F.M.; Liegler, T.; Richman, D.D.; et al. Select host restriction factors are associated with HIV persistence during antiretroviral therapy. AIDS 2015, 29, 411-420. [CrossRef]

214. Raposo, R.A.S.; Abdel-Mohsen, M.; Deng, X.; Hecht, F.M.; Pilcher, C.D.; Pillai, S.K.; Nixon, D.F. Dynamic regulation of host restriction factor expression over the course of HIV-1 infection in vivo. J. Virol. 2014, 88, 11624-11629. [CrossRef] [PubMed]

215. Kimura, T.; Jain, A.; Choi, S.W.; Mandell, M.A.; Johansen, T.; Deretic, V. TRIM-directed selective autophagy regulates immune activation. Autophagy 2017, 13, 989-990. [CrossRef]

216. Yap, M.W.; Dodding, M.P.; Stoye, J.P. Trim-cyclophilin A fusion proteins can restrict human immunodeficiency virus type 1 infection at two distinct phases in the viral life cycle. J. Virol. 2006, 80, 4061-4067. [CrossRef]

217. Walker, J.E.; Chen, R.X.; McGee, J.; Nacey, C.; Pollard, R.B.; Abedi, M.; Bauer, G.; Nolta, J.A.; Anderson, J.S. Generation of an HIV-1-resistant immune system with CD34+ hematopoietic stem cells transduced with a triple-combination anti-HIV lentiviral vector. J. Virol. 2012, 86, 5719-5729. [CrossRef]

218. Anderson, J.; Akkina, R. Human immunodeficiency virus type 1 restriction by human-Rhesus chimeric tripartite motif $5 \alpha$ (TRIM5 $\alpha$ ) in CD34+ cell-derived macrophages in vitro and in T cells in vivo in severe combined immunodeficient (SCID-hu) mice transplanted with human fetal tissue. Hum. Gene Ther. 2008, 19, 217-228. [CrossRef]

219. Morgan, R.A.; Gray, D.; Lomova, A.; Kohn, D.B. Hematopoietic stem cell gene therapy: Progress and lessons learned. Cell Stem Cell 2017, 21, 574-590. [CrossRef] [PubMed]

220. Nardacci, R.; Amendola, A.; Ciccosanti, F.; Corazzari, M.; Esposito, V.; Vlassi, C.; Taibi, C.; Fimia, G.M.; Del Nonno, F.; Ippolito, G.; et al. Autophagy plays an important role in the containment of HIV-1 in nonprogressor-infected patients. Autophagy 2014, 10, 1167-1178. [CrossRef]

221. Campbell, G.R.; Spector, S.A. Vitamin D inhibits human immunodeficiency virus type 1 and mycobacterium tuberculosis infection in macrophages through the induction of autophagy. PLoS Pathog. 2012, 8, e1002689. [CrossRef] [PubMed]

222. Campbell, G.R.; Bruckman, R.S.; Chu, Y.-L.; Trout, R.N.; Spector, S.A. SMAC mimetics induce autophagy-dependent apoptosis of HIV-1-infected resting memory CD4+ T Cells. Cell Host Microbe 2018, 24, 689-702.e7. [CrossRef]

223. Espert, L.; Varbanov, M.; Robert-Hebmann, V.; Sagnier, S.; Robbins, I.; Sanchez, F.; Lafont, V.; Biard-Piechaczyk, M. Differential role of autophagy in CD4 T cells and macrophages during X4 and R5 HIV-1 infection. PLoS ONE 2009, 4, e5787. [CrossRef] [PubMed]

224. Zhou, D.; Masliah, E.; Spector, S.A. Autophagy is increased in postmortem brains of persons with HIV-1-associated encephalitis. J. Infect. Dis. 2011, 203, 1647-1657. [CrossRef] [PubMed]

225. Gupta, M.K.; Kaminski, R.; Mullen, B.; Gordon, J.; Burdo, T.H.; Cheung, J.Y.; Feldman, A.M.; Madesh, M.; Khalili, K. HIV-1 Nef-induced cardiotoxicity through dysregulation of autophagy. Sci. Rep. 2017, 7, 1-15. [CrossRef] [PubMed]

226. Remick, J.; Georgiopoulou, V.; Marti, C.; Ofotokun, I.; Kalogeropoulos, A.; Lewis, W.; Butler, J. Heart failure in patients with human immunodeficiency virus infection: Epidemiology, pathophysiology, treatment, and future research. Circulation 2014, 129, 1781-1789. [CrossRef]

227. Tahrir, F.G.; Shanmughapriya, S.; Ahooyi, T.M.; Knezevic, T.; Gupta, M.K.; Kontos, C.D.; McClung, J.M.; Madesh, M.; Gordon, J.; Feldman, A.M.; et al. Dysregulation of mitochondrial bioenergetics and quality control by HIV-1 Tat in cardiomyocytes. J. Cell. Physiol. 2018, 233, 748-758. [CrossRef] [PubMed]

228. Nardacci, R.; Ciccosanti, F.; Marsella, C.; Ippolito, G.; Piacentini, M.; Fimia, G.M. Role of autophagy in HIV infection and pathogenesis. J. Intern. Med. 2017, 281, 422-432. [CrossRef]

229. Brew, B.J.; Chan, P. Update on HIV dementia and HIV-associated neurocognitive disorders. Curr. Neurol. Neurosci. Rep. 2014, 14, 468. [CrossRef] 
230. Clifford, D.B.; Ances, B.M. HIV-associated neurocognitive disorder. Lancet Infect. Dis. 2013, 13, 976-986. [CrossRef]

231. Mehla, R.; Chauhan, A. HIV-1 differentially modulates autophagy in neurons and astrocytes. J. Neuroimmunol. 2015, 285, 106-118. [CrossRef]

232. Zhang, G.; Luk, B.T.; Hamidy, M.; Zhang, L.; Spector, S.A. Induction of a $\mathrm{Na}^{+} / \mathrm{K}^{+}$-ATPase-dependent form of autophagy triggers preferential cell death of human immunodeficiency virus type-1-infected macrophages. Autophagy 2018, 14, 1359-1375. [CrossRef] [PubMed]

233. Campbell, G.R.; Spector, S.A. Toll-like receptor 8 ligands activate a vitamin D mediated autophagic response that inhibits human immunodeficiency virus type 1. PLoS Pathog. 2012, 8, e1003017. [CrossRef]

234. Shoji-Kawata, S.; Sumpter, R.; Leveno, M.; Campbell, G.R.; Zou, Z.; Kinch, L.N.; Wilkins, A.D.; Sun, Q.; Pallauf, K.; MacDuff, D.; et al. Identification of a candidate therapeutic autophagy-inducing peptide. Nature 2013, 494, 201-206. [CrossRef]

235. Coulon, P.-G.; Richetta, C.; Rouers, A.; Blanchet, F.P.; Urrutia, A.; Guerbois, M.; Piguet, V.; Theodorou, I.; Bet, A.; Schwartz, O.; et al. HIV-infected dendritic cells present endogenous MHC class II-Restricted antigens to HIV-specific CD4+ T cells. J. Immunol. 2016, 197, 517-532. [CrossRef] [PubMed]

236. Chemali, M.; Radtke, K.; Desjardins, M.; English, L. Alternative pathways for MHC class I presentation: A new function for autophagy. Cell. Mol. Life Sci. 2011, 68, 1533-1541. [CrossRef]

237. Harris, R.S.; Hultquist, J.F.; Evans, D.T. The restriction factors of human immunodeficiency virus. J. Biol. Chem. 2012, $287,40875-40883$. [CrossRef] [PubMed] 